Portland State University

PDXScholar

$1-21-1985$

\title{
A Comparison of Motoric and Linguistic Features in Graphic Samples of Fluent and Nonfluent Aphasic Persons Over Three Time Intervals
}

Babette Fisher

Portland State University

Follow this and additional works at: https://pdxscholar.library.pdx.edu/open_access_etds

Part of the Linguistics Commons, and the Speech Pathology and Audiology Commons Let us know how access to this document benefits you.

Recommended Citation

Fisher, Babette, "A Comparison of Motoric and Linguistic Features in Graphic Samples of Fluent and Nonfluent Aphasic Persons Over Three Time Intervals" (1985). Dissertations and Theses. Paper 3435. https://doi.org/10.15760/etd.5318

This Thesis is brought to you for free and open access. It has been accepted for inclusion in Dissertations and Theses by an authorized administrator of PDXScholar. Please contact us if we can make this document more accessible: pdxscholar@pdx.edu. 
AN ABSTRACT OF THE THESIS OF Babette Fisher for the Master of Sclence in Speech Communication with an emphasis in Speech-Language Pathology and Audlology presented January 21,1985 .

Title: A Comparison of Motoric and Linguistic Features in Graphic Samples of Fluent and Nonfluent Aphasic Persons Over Three Time Intervals.

APPROVED BY MEMBERS OF THE THESIS COMMITTEE:

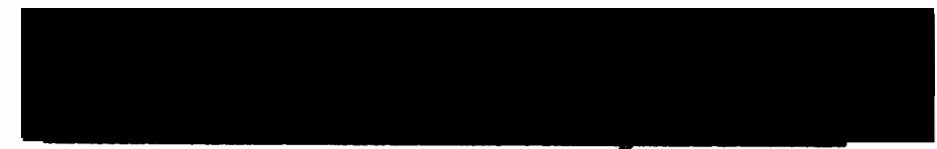

Lee Ann Golper, Co-Chairman

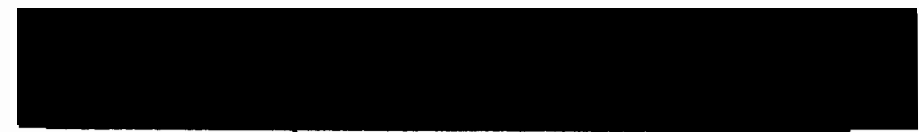

Mary Gordon, Ca-Chairman

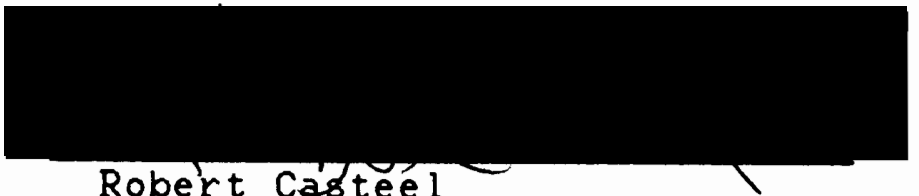

Robert Casteel

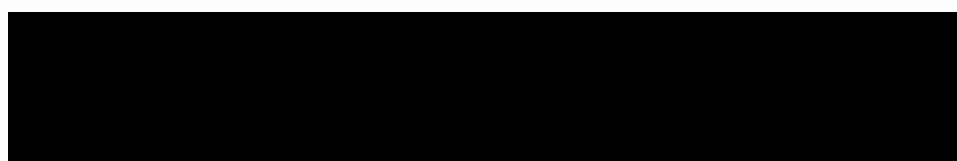

Thomas Dleterlch

The purpose of this study was to compare the graphic production of fluent and nonfluent aphasic groups in terms 
of motoric and 1 inguistic characteristics at three intervals of recovery, and to analyze change over time after combining the fluent and nonfluent aphasic groups. Evaluations were made at roughly one, three and six months post onset. Writing samples from a total of 25 subjects included 10 fluent aphasic patients, 10 nonfluent aphasic patients and a reference group of 5 age matched nonneurologically impaired subjects. Samples of written responses were taken in a retrospective manner from flles of patients who had recelved speech pathology treatment at the Portland Veterans Administration Medical Center within the preceding 12 year period. All written samples were in response to the Porch Index of Communicative Ability (BICA) graphic subtests. The normal reference group was administered the PICA once and written subtests were included in the sampling series for graphic analysis.

All of the aphasic subjects had suffered thromboembol ic cerebrovascular accidents that involved the left hemisphere of the brain. The aphasic individuals had an equivilant range and mean for PICA Overall severity percentlle at one month post onset, ranged in age from 52 to 65 years of age, were right handed and were premorbidly literate.

Previously determined criteria were applied to subtest samples by a single judge who evaluated motoric and linguistic features of each subtest. Variable mean scores were determined and appropriate statistical measures were 
applied. Performances of the normal group subjects were not included in data analysis, but were used to illustrate graphically how the findings compared to normal.

When comparing the fluent and nonfluent group performances, it was noted that differences between the two groups for all but two variables were not significant at any of the three sampling times. The two statistically significant variables were "unclassifiable" word types (meaningless word forms of two or more letters) and letter substitution errors of spelling. It was noted that most differences occurred in $T$ ime $I$, but by $T$ ime $I I$ and again at Time III, the groups were largely indistinguishable. Linguistic recovery appeared early in recovery (within $1-3$ months) while motoric improvements occurred more slowly, and inter-group motorlc differences were slight.

After combining the two groups, most IInguistic measurement changes occurred between Time I and II (about 45 percent), while fewer motoric score changes occurred during this same time about 30 percent). In general, the combined group's graphic production mean scores improved over time. The aphaslc group increased the number of recognlzable words produced, words spelled correctly, and they attempted to write more while decreasing the number of literal paraphaslas, neologlsms, and perseverations. Motorically, writing tended to moderate in slze, while tremorous and nonfluid writing decreased. 


\section{A COMPARISON OF MOTORIC AND LINGUISTIC FEATURES IN GRAPHIC SAMPLES OF FLUENT AND NONFLUENT APHASIC PERSONS OVER THREE TIME INTERVALS}

\section{by}

\section{BABETTE FISHER}

A thesis submitted in partial fulfillment of the requirements for the degree of

MASTER OF SCIENCE IN SPEECH COMMUNICATION: EMPHASIS IN SPEECH-LANGUAGE PATHOLOGY AND AUDIOLOGY

$$
\text { Portland State University }
$$


TO THE OFFICE OF GRADUATE STUDIES AND RESEARCH:

The members of the Committee approve the thesis of Babette Fisher presented January 21, 1985.

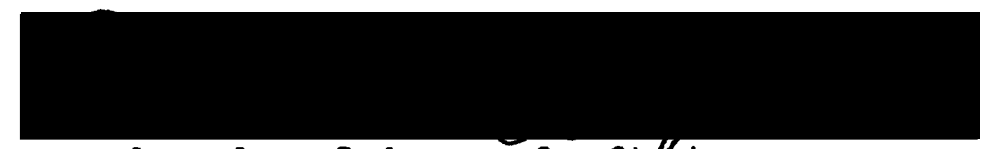

Lee Ann Golper, Co-ChGirman

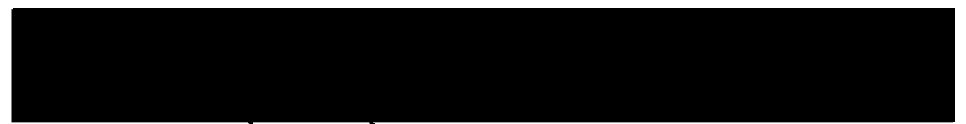

Mary Gorgdn, Co-Chairman

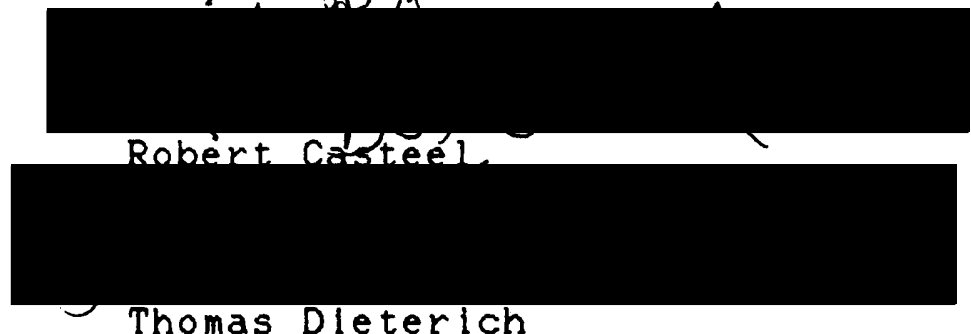

\section{APPROVED :}

Theodore G. Grove, Chair, Department of Speech Communication

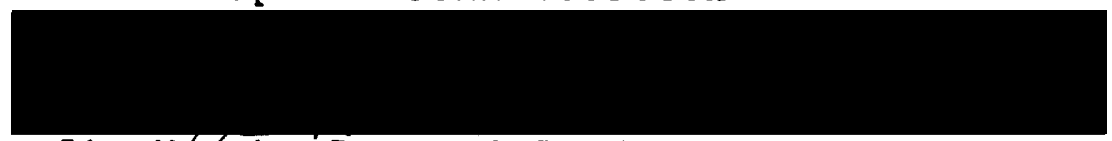

Jim Heath, Dean of Graduate Studies and Research 


\section{ACKNOWLEDGEMENTS}

I am especially grateful for Dr. Lee Ann Golper's assistance in creating and completing this project. My thanks too, for Mary Gordon's cheerful support and practical advice which made the task easier. I appreciate the suggestions and support of the other members of my committe, Dr. Robert Casteel and Dr. Thomas Dieterich.

Special thanks to my children, Stephanie and Jeffrey, for their patience, love and chocolate chip cookies. 
TABLE OF CONTENTS

PAGE

ACKNOWLEDGEMENTS . . . . . . . . . . . . . . . . Iil

LIST OF TABLES . . . . . . . . . . . . . . . . v1

LIST OF FIGURES . . . . . . . . . . . . . . . . . vIl

CHAPTER

I INTRODUCTION $\cdot \cdot \cdot \cdot \cdot \cdot \cdot \cdot \cdot \cdot \cdot \cdot \cdot \cdot \cdot \cdot 1$

I I REVIEW OF THE LITERATURE . . . . . . . . . . 5

Classlfication of Aphasic Behavior . . . 5

Writing and Aphasia.......... 11

Characteristics, Remediation and Recovery of Wrlting in Aphasia ....... 19

Summary ............... 28

I I METHODS AND PROCEDURES . . . . . . . . . . 31

Subjects .............. 31

Procedures . . . . . . . . . . . 35

Data Measurement and Analys ls . . . . 37

IV RESULTS AND DISCUSSION ........... 41

Results . . . . . . . . . . . . 41

Fluent and Nonfluent Group Comparison.. 41

Combined Group Changes . . . . . . 42

Discussion ........... . . 50 
Between-Group Comparisons . . . . .

Linguistic Varlables for subtest $A$

Linguistic Variables for Subtests $B-E$

Motoric Varlables

Between-Time Summary

Inter-Group Comparison Summary

Between-Time Interval Differences.

Lingulstlc Varlables for Subtest $A$

78

LIngulstic Varlables for Subtests B-E

Motoric Variables

V SUMMARY AND IMPLICATIONS . . . . . . . . 93

Summary . . . . . . . . . . . . 93

Clinical Implications......... 95

Implications for Further Research . . . 96

REFERENCES . . . . . . . . . . . . . . . . 97

APPENDICES . . . . . . . . . . . . . . 102 


\section{LIST OF TABLES}

TABLE

PAGE

I Characteristics of Fluent Aphaslc Subjects . . 33

I Characteristics of Nonfluent Aphasic Subjects . 34

II Between Group Comparisons at Three TIme Intervals................ 43

IV Between-Time Change for Comblned Group,

Lingulstic Varlables... . . . . . . . 44

$V$ Between-Time Change for Comblned Group,

Lingulstic Variables... . . . . . . . 45

VI Between-Time Change for Combined Group,

Lingulstic Varlables........... . 46

VII Between-TIme Change for Combined Group

Lingulstic Varlables... . . . . . . . 4 47

VII Between-Time Change for Comblned Group

Motorlc Varlables. . . . . . . . . . . 48

IX Between-Time Change for Combined Group

Motorlc Varlables . . . . . . . . . . . 49

X Rank Order of Words and Total Words . . . . . 60 


\section{LIST OF FIGURES}

F I GURE

PAGE

Group Comparisons

1. Linguistic Word Types, Tlme I. . . . . . 53

2. Linguistic Word Types, Time II . . . . . 54

3. Linguistic Word Types, TIme III . . . . . 55

4. Comparison of Fluent and Nonfluent Aphasics and Normal Subjects, Time I... . . 56

5. Comparison of Fluent and Nonfluent Aphaslas and Normal Subjects, Time II . . . . . 57

6. Comparison of Fluent and Nonfluent Aphasics and Normal Subjects, Time III... . . . 58

7. Linguistic: Spelling Subtest A . . . . . 59

8. Linguistic: Spelling Subtests, B-E . . . . 67

9. Linguistic: Word Error Type . . . . . . . 69

10. Motoric: Letter Execution......... 70

11. Motorlc: Letter Slze . . . . . . . . 73

12. Motorlc: Line Execution . . . . . . . . 75

13. Motoric: Letter Style... . . . . . 76

\section{Combined Groups}

14. Linguistic: Word Types . . . . . . . . 80

15. Comparison of Normal and Aphasic Groups, Word Types, Time I.......... 81

16. Comparison of Normal and Aphasic Groups, Word Types, TIme II............ 82 
17. Comparison of Normal and Aphasic Groups, Word Types, Time III . . . . . . . . 83

18. Linguistic: Spelling, Subtest A . . . . . 85

19. Linguistic: Spelling, Subtests B-E . . . . 87

20. Linguistic: Word Error Type . . . . . . . 87

21. Motoric: Letter Execution.......... 89

22. Motoric: Letter Size ............ 91

23. Motoric: Line Execution ........... 91

24. Motoric: Letter Style... . . . . . . 91 
CHAPTER I

\section{INTRODUCTION AND STATEMENT OF PURPOSE}

\section{Introduction}

Writing is an extraordinarlly complex process dependent upon the blending of several cognitive and motor functions. Many cognitive processes, such as sensory perception, lingulstic knowledge, inner speech, and memory come together in the execution of written language. Writing is a signal system with features both connected to and distinct from oral language. Knowledge of the rules of spoken language (phonology, morphology, and syntax) are necessary for written language, yet this knowledge does not assure successful writing, for the graphlc code has unique features and is not a simple transcription of the oral code. It appears that the structural rules of written language can be learned only after phonology, morphology, and syntax of oral language are learned (Welgl, 1975). The ontogenesis of written language occurs later than oral language in development, and writing is a fraglle skill readlly disturbed by disorders or damage to the central nervous system (Smith, 1971).

Disordered writing is termed "agraphla" (Elsenson, 1973; Perkins, 1977) and is commonly assoclated with 
cerebral damage. The term has been applled to describe disruptions of both motorlc and linguistic features in written expression (Marcle and Hecaen, 1979). Agraphia is usually found in association with aphasia, a general language deficlt resulting from brain injury (Schuell, Jenkins, and Jimenez-Pabon, 1964). Aphasic Individuals are Impaired in thelr ability to formulate symbolic material percelved auditorlly, visually, or tactually, and are Impalred when speaklng, wrlting, or gesturing (Brookshire, 1978). Some degree of writing disruption invarlably follows the disruption of speaking in aphasia culatowska, Baker and Stern, 1979) but, according to Marcle and Hecaen (1979), the writing disruption frequently differs in type and intensity from the oral disruption. Porch (1981) noted that wrltten tasks are more difflcult than gestural or verbal tasks. Schuell, Jenkins, and Jimenez-Pabon (1964) found that wrlting impalrment was characteristlc of all aphasla subgroups in Schuell's classlflcation system. Smith (1971) studied recovery in aphasia examining both speech and writing. He found writing to be the last skill to recover, and some aphaslc Individuals never recover functional writing, even though they may develop functional verbal communication.

Aphasia is sometimes categorlzed as fluent or nonfluent, based on speech output characteristics and the degree of auditory comprehension deficlt (Goodglass and Kaplan, 1972, a). The most common type of nonfluent 
aphasla is Broca's aphasla, In whlch speech is described as halting and labored, with misarticulations and a proportionately greater number of content than functor words. According to Brookshire (1978), handwriting of a nonfluent aphaslc Individual would usually be poor and written content would resemble verbal content. The Individual with fluent aphasia is sald to have good articulation, speech prosody, and retained grammatical relationships in sentences, but in most cases there is a lack of meaningful content in verbal utterances and the individual is somtimes described as having "empty speech." Handwriting would be mechanically good, but there may be a notable lack of meaningful content in written expression resembling the non-contentlve verbal utterances (Brookshlre, 1978).

Al though there seems to be agreement regarding the universality of writing disorders in aphasia, relatively little research has been reported regarding relationship between types of aphasia and writing disorders, or graphic changes that occur during aphasia recovery. Only a few studies of recovery patterns for graphlc abllities can be found in aphasia research. Information regarding these aspects would ald in treatment-planning and determining prognosis for recovery of written expression in aphasia.

\section{Statement of Purpose}

This study investlgated the relationship between 
motoric and linguistic error types within written samples of fluent and nonfluent aphasic groups at intervals of recovery.

Speciflcally, the following questions were examined:

1. Is there a slgnflcant difference in motorlc and linguistic features of graphic responses between fluent and nonfluent aphasic patients at three Intervals of recovery in response to Identical test stimulus?

2. Is there a slgniflcant change over three evaluation times in graphic production of aphasic individuals? 


\section{CHAPTER II}

\section{REVIEW OF THE LITERATURE}

This chapter highlights some major findings and theories within the literature related to agraphia and aphasia. A description of a commonly-used classification system for aphasia is provided. A brief historical review of the study of agraphia and normal and disordered writing are discussed along with the $11 \mathrm{mlted}$ research speclflcally examining writing abilities in aphasic persons. Finally, studies comparing written and oral expressive abilities (Friederici, Schoenle, and Goodglass, 1981; Gibson, Gruner, Kibler, and Kelly, 1966; Goodglass and Hunter, 1970; Hier and Mohr, 1977) and studies making intermodality comparlsons in recovery (Butfleld and Zangwill, 1946; Ken in and Swisher, 1972; Porch, 1981; Smith, 1971) are examined. These findings and the theoretical statements made by researchers in thls area are reviewed and summarlzed to provide background for the questions proposed in this study.

\section{Classlfication of Aphasic Behavior}

Aphasia is described as "acquired impairment of language processes underlying receptive and expressive 
modalitles and caused by damage to areas of the brain which are primarlly responslble for language function"

(Davis,1983). Historlcally, clinlclans and researchers have made frequent and varied efforts to classify aphasia into tyoes or syndromes. One such classification system differentiates aphasic behavior on the basis of verbal output, that is, whether or not speech output is fluent or nonfluent (Geschwind, 1971; Goodglass and Kaplan, 1972a). Within this system coften referred to as the "Boston Classification System"), different syndromes are discussed as variants of fluent or nonfluent aphasia. There is some disagreement as to the validity of these syndrome categories and type classifications (Davis, 1983). Goodglass and Kaplan (1972a) have noted that only about onehalf of all aphasic patients can be classified into this schema. Many aphasiologists have preferred to point out the vast similarities among aphasic persons rather than attempt to separate aphasia into arbitrary categories (Darley, 1982). However, much of the literature discussing writing in aphasia has included subject groups classified by the Boston system. To better understand this literature and relate findings to the present questions, a description of fluent and nonfluent syndromes, according to Geschwind (1971) and Goodglass and Kaplan (1972a) is provided.

\section{Nonfluent Aphasla}

Individuals with nonfluent aphasia are presumed to 
have damage to the anterior speech areas of the left cerebral hemisphere. Speech is described as "interrupted, awkwardly articulated with great effort" (Goodglass and Kaplan, 1972a). The nonfluent category includes Broca's, global, and transcortlcal motor aphasla (Davls, 1983). Written language of nonfluent patients is said to be simllar to thelr, spoken language though more restrlcted in form and content. Studies of writing among nonfluent aphaslc persons usually focus upon subjects with Broca's aphasia, while writing in global and transcortical motor aphasia has rarely been examined.

Broca's Aphasla. This type of aphasla consists of relatively good comprehension but "awkward" articulation and vocabulary utilizing simple and overlearned forms of of grammar (Goodglass and Kaplan, 1972a). The few words produced by these aphasic persons may carry the intent of the message (Davis, 1983) such that speech production might be telegraphlc (Geschwind, 1971). In spontaneous conversation, the speech of persons with Broca's aphasia is usually marked with distortions and transpositons of phonemes (speech sounds). During early stages of recovery, object naming may improve to a functional level, while syntax remains Impaired (Goodglass and Kaplan, 1972a).

Global Aphasta. Individuals with this type of aphasla demonstrate severe depression of language function in all modalitles (Davis, 1983). These individuals do not appear to comprehend language nor do they produce 
functional speech though nonpropositonal utterances (nonmeaningful, stereotypic utterances) may occcur (Davis, 1983).

Transcortical Motor Aphasia. This type of nonfluent aphasia might sound very much like Broca's aphasia in spontaneous conversation. Like Broca's aphasia, persons with transcortical motor aphasia are described as having stumbling, repetitive speech and relatively good auditory comprehension. The differentiating factor of transcortical motor aphasia is a notable retained remarkable ability to repeat utterances fluently that can not be said volitionally (Goodglass and Kaplan, 1972a).

\section{Eluent Aphasia}

The category of fluent aphasia is more diverse than the nonfluent aphasia classifications. Fluent aphasia classifications include Wernicke's, conduction, anomic, and transcortical types of aphasia (Basso, Capitani, and Zanobio, 1982). Brain lesions occurring in areas posterior to the Rolandic fissure, sparing Broca's area, are said to produce fluent types of aphasia cGoodglass and Kaplan,1972a). Brookshlre (1978) predicts that written language of fluent aphasla would be mechanlcally good, but lacking in meaningful content words.

Wernlcke's Aphasla. The most common syndrome of the fluent aphasia's, Wernicke's aphasia, is described as the result of damage to the posterior portion of the first 
temporal gyrus of the left hemisphere (Goodglass and Kaplan, 1972a). Because the posterior location of the lesion may spare the frontal motor areas, these patients may or may not display hemiparesis (weakness on the contralateral side of the body) and may continue to use the ir right hand for writing (Goodglass and Kaplan, 1972a). The critical characteristics of thls syndrome are impalred auditory comprehension and fluently articulated "paraphaslc" speech (Goodglass and Kaplan, 1972a). Paraphasia may include sound transpositions (literal paraphasia, e.g., "sork" for "fork") and word substitutions (verbal paraphaslas, e.g., "fork" for "spoon")(Goodglass and Kaplan, 1972a). These patients generally can not repeat a stimulus and attempts to do so frequently bear no relationshlp to the model stimulus (Davis, 1983). The reading and writing of Wernlcke's aphasic individuals is predicted to be as severely impaired as the ir speech (Goodglass and Kaplan, 1972a).

Conduction Aphasia. In this syndrome repetition is disproportionately severely impaired compared to a near normal level of auditory comprehenslon (Davis, 1983; Goodglass and Kaplan, 1972a). Comprehension and expressive abilities are usually quite good though there may be occasional word finding difficulties and phonemic paraphaslas (sound substitutions within words).

Anomic Aobasia. The major feature of anomic aphasia is the prominence of word finding difficulty in the context 
of fluent, grammatically well-formed speech (Goodglass and Kaplan, 1972a). This disorder differs from Wernicke's aphasla in that speech is free of 1 lteral and verbal paraphasias and there is intact auditory comprehension. These patients might speak freely but have a notable lack of substantive content words in their speech (Goodglass and Kaplan, 1972a).

Transcortical Sensory Aohasla. This rare syndrome is characterlzed by fluent paraphasic speech with a retalned ability to repeat (Davis, 1983). Typlcally, these individuals do not initiate speech on their own. When addressed, they often answer with well-articulated, but irrelevant, paraphasia. These patients frequently display echolalia crepeating a stimulus rather than responding appropriately to it). According to Davis (1983), it is as though the mechanism of speech has been separated from the intentions and meanings generated in the rest of the brain.

In summary, aphasla is sald to be classiflable on the basis of verbal output into either fluent or nonfluent categories. Fluent aphaslc individuals would be expected to produce easlly artlculated but paraphasic speech with severe to mildly impalred auditory comprehension. Nonfluent aphasic individuals might demonstrate awkward articulation and a limited spoken vocabulary but relatively preserved auditory comprehension.

Before proceeding to describe recent research related to aphasia and writing, a historical overvlew of approaches 
to the study of agraphla with aphasla is provided as further background for the questions posed in this study.

\section{Writing and Aphasla}

\section{Historical Overvien}

In the mid 1800 s neurologists began to propose theories regarding the relationship between impalred speech and impaired writing after cerebral injuries. Ulatowska, Baker, and Stern (1979) cited Marce as the first researcher, in 1856, to specifically examine disordered writing in brain injured persons. Benedikt (1865) subsequently suggested that the loss of voluntary motor association between the idea of words and the graphic or oral production of words is responsible for the association of oral paraphasla and agraphia (Marcie and Hecaen, 1979). The term "agraphia", as a descriptor for writing disorders resulting from cortical lesions, was first introduced in 1869 by Ogle, who observed that some aphasic individuals can write words they can not say and, thus, felt the cerebral mechanism underlying speech and writing must be separate (Marcle and Hecaen, 1979; Smlth, 1971). In 1891, when describing an aphasic/agraphic patient, Dejerine stated that writing disorders are the direct result of language Impalrment (Marcie and Hecaen, 1979). Later Goldstein (1948) discussed two stages of writing, l.e., praxic and linguistic. He suggested that in primary agraphla, motor and graphlc acts are affected because the 
hand can no longer perform acts "ordered" by the brain; while secondary agraphia can be correlated with (or secondary to) the language deflclts (Goldsteln, 1948; Marcle and Hecaen, 1979).

Support for the notion that agraphia is both a disorder associated with aphasia, and less commonly, an impairment that can occur without aphasia can be found in more recent research I iterature; however, modern aphasiologists disagree in the ir views regarding the relationship between aphasia and agraphia. A summary of some recent research in agraphia illustrates the areas of debate.

\section{Theoretical Perspective}

Traditionally, written language has been assessed in terms of normal development skills by educational psychologists and linguists. Such research includes studying written samples and measuring grammatic units, complexity, and vocabulary development. This perspective assumed that written language was simply speech written down, and the proper way to study language, whether normal or disordered, was in its oral form culatowska, Baker and Stern, 1979). Recently, however, researchers are beglnning to conslder the unlque features of oral versus written language. Speech has an acknowledged biologlcal and historical precedence over writing, but research is demonstrating a number of differences between the two 
modalities, especlally for syntax and lexlcal features (Ulatowska, Baker and Stern, 1979). Although written language is Influenced by growth, development, and perhaps maintenance of oral language, it is a somewhat different form of communication (Smith, 1975; Smith, 1971). Gibson, Gruner, Kibler and Kelly (1966) compared the writing and speaking styles of college students and found that their written language tends to be characterized by a greater number of different words, words with more syllables, longer sentences and fewer personal words than that of spoken language.

Ulatowska, Hildebrand and Haynes (1978) compared the spoken and written language of eleven mildly aphasic subjects in isolated sentences and connected discourse to a control group doing the same tasks. The aphaslc subjects in this study were observed to produce less complex language than the controls, especially in writing. The aphasic subjects produced more preposition and semantic errors than the controls, with the greater difference being in written language. Overall, the aphasic subjects produced fewer errorless word sequences in writling than in spoken sequence.

Some theorists have suggested that the graphemic system becomes independently autonomous from the phonological system during the development of reading and writing skills (Shallice, 1981). The assumption is that meaning may be extracted directly from visual or written 
output without phonological mediation. Welgl (1975) stated that since oral language comes before written language, it mlght be assumed that further cerebral zones become integrated with those already developed for oral language, and these cortical areas Involved in reading and writing are larger than those involved in oral language. During developmental processes of reading and writing, Weigl (1975) postulated a consistent interaction between the graphic/phonemic areas of the brain, but as the individual becomes more skllled in reading and writing, these centers become increasingly autonomous. Further, he suggested intercerebral function can be reactivated in case of need, thus the experienced wrlter is not conscious of motor control when writing, but this reduction of consciousness may vary with the degree of difflculty of the written material.

Writing can be learned after cerebral maturation takes place, and Welgl (1975) suggests thls may be the reason rules governing these later acquisitions are more labile and more subject to pathological intervention than baslc rules of language demonstrated by oral production. It is difficult to test linguistlc differences between oral and written expression in aphasic persons, due to the paucity of their output in elther modality. Theorles regarding the possible "dissociations" and interdependencles of mental processes underlylng oral and written language, and the strategles used by aphasic 
persons when they attempt to say versus to write a word, have largely come from observations of single patients or small groups of patients with varlous etiologles and types of aphasia. Frequently, broad generalizations are made from experiments using only a few simple tasks involving single word outputs. Some studies have focused on only mildly aphasic subjects (Keenan, 1971; Ulatowska, Hildebrand, and Haynes, 1978) and other studies compare small numbers of different types of aphasic subjects (Bub and Kertesz, 1982; Friederic1, Schoenle, and Goodglass, 1981; Hier and Mohr, 1977) or have examined only globally aphaslc persons (Brown, Leader and Blum, 1983; Mohr, Sidman, Stoddard, Leicester, and Rosenberger, 1973).

Although one could argue that studies of pathologic states, like aphasia, should not be compared to the ontogenesis of graphlc-oral language development, a support for the notion that a degree of autonomy exists between these two modalities can be found in studies of dissociations between oral and written language in aphasia.

\section{Disseclation of Written and Oral Language in Aphasia}

Several researchers have descrlbed cases in which written naming is superlor to oral naming as evidence for autonomous phonological/graphemic systems. Mohr et al., (1973) studied three globally aphasic individuals who demonstrated persistently worse deficits in oral naming 
than wrltten naming. After observing these patients for two to six years, the authors developed a deficit profile to describe global aphasla which included: 1) initial mutism and with preserved ability to match visually and tactually; 2) gradual emergence of naming and an increase in the ability to match auditory to visual letters; 3 ) continued superiorlty of written over oral naming; and 4) superlority of performances involving sounds of words over sounds of letters. Most theories of aphasia state that written naming is dependent upon oral naming and is expected to be at least as severely Impalred; however, Mohr et al. (1973) found a demonstrable independence of oral and written naming for globally impaired subjects. They suggested their three subjects were not the exception, but were typical of global aphasla.

Friederici, Schoenle and Goodglass (1981) presented plcture naming tasks to eight Broca's and four Wernicke's aphasla patients. The Broca's aphaslc subjects, in general, performed higher in writing than in oral naming, but there was great varlance within the group since only half the Broca's aphaslcs generally performed higher in written than in oral naming. Oral and written performance did not differ significantly for the Wernicke's patients. Error patterns of these patients indicated those Broca's aphasic subjects who were better in writing than oral naming showed more graphemically and semantically motivated errors than aphasics who were better in oral than written 
naming, the latter producing more phonemlcally motlvated errors. These authors suggest that the dissociation, partlcularly in the subgroup of superior writing to oral production, provides evidence that in the processing of some lexical items written performance can be spared, thus consistent with the assumption of a direct pathway for mental lexicon to the graphemic system. This concept would support the theory of a dual encoding system at the single word level, implying a direct route from the mental lexicon to the graphemic system in parallel with a route mediated by the phonemic system.

Hier and Mohr (1977) compared written and spoken performance of a Wernicke's aphasic person and noted that written naming was spared, although oral naming was not, and there was some superiorlty of reading comprehension to auditory comprehension. Shallice (1981) in a single case study, investigated a patient with conduction aphasia who demonstrated dissociation between a well-preserved abllity to write words ( 94 percent correct) and inability to write nonsense syllables ( 18 percent correct). This individual could maintain the nonsense word or syllable in memory and say it after he falled to write it, thus his difficulty writing non-words can not be explained by perceptual or memory problems.

Beauvois and Derouesne (1981) described a patient whose acquired agraphia consisted solely of a difficulty in spelling words having any irregular or ambiguous phoneme- 
grapheme transformations, with the writing of regular words and nonsense syllables being preserved. These authors concluded that writing a word can be performed elther by using a direct lexical method of obtaining spelling (the lexical route) or by "sounding out" the word in phonemes and employing phoneme grapheme transformations (the phonological route). They felt their patient had a specific deficit of the lexical route. Bub and Kertesz (1982) reported a case of incongruous written over oral naming in a fluent aphasic patient. Written naming for single words was found to be markedly superior to spoken naming, but rhyme matching task performance indicated impaired ability to retrieve sound components and nonlexical phonological processing was severely impaired when writing to dictation. The authors suggested that written naming can occur through direct conversion of lexical information into graphemic code, even when the underlying sound component of words is not retrleved.

Basso, Taborelli and Vignolo (1978) found only 14 out of 500 left brain damaged patients demonstrated a clear dissoclation between oral and written language. Of those 14 subjects, speech was selectively impalred in 7 and writing selectively impaired in the other 7 . The authors felt these results provided evidence for a dissoclation between oral and written writing among a small percentage of left brain damaged patients. 
In summary, there is evidence to suggest that: 1) the development of graphic language incorporates processes that are both dependent upon and independent from processes underlying oral language; 2) dissociative processes can be found among aphasic persons; 3 ) oral and written expression may have some degree of independence at the one word level and 4) that when writing a single word, aphasic Individuals may employ different strategies, either a lexical route or phonological route.

Characterlstics. Remedlation and Recovery of Writing in Aphasia

Although evidence exists for dissociations between oral and written language in aphasia, at least at the one word level, it has been assumed that writing impairments wll be similar in form and content to the aphasic individual's disordered oral production (Goodglass and Hunter, 1970; Hellman, 1975; Ulatowska, Hlldebrand, and Haynes, 1978). The patlent may forget how words should look and how to form particular letters. He may produce assoclation errors (e.g., "spoon" for "fork"), may substitute words that sound like the target words and may make many more attempts at self correction (Darley, 1982). These errors generally do not occur randomly but may demonstrate an orderly, rule based breakdown and Impalred abillty to access and retrieve linguistic rules (Darley, 1982; Rubin and Bollinger, 1983). The following summarlzes 
findings related to agraphla with aphasia with speciflc attention given to the kinds of errors found in aphaslc writing and treatment and recovery studies.

\section{Characteristics of Aohasic Writing}

Any degree of aphasia produces some writing disruption (Keenan, 1971; Smith, 1971; Ulatowska, Hildebrand, and Haynes, 1978). Generally writing defects are markedly greater than oral production, auditory comprehension, and reading impairments in both hemiplegic and non-hemiplegic patients (Smith, 1971; Duffy and Ulrich, 1976). Bub and Kertesz (1982) found that speech and writing are impaired in qualitatively identical ways, although writing is generally performed more poorly than speech. However, Shallice,(1981) suggested that Wernicke's aphaslcs do not always have as severe a deficit with writing as with speaking. Dissociation studies discussed earlier, suggest differences may be found between oral and written productions of aphasic persons. Goodglass and Hunter (1970), when comparing the oral and written production of a Wernicke's aphasic and a Broca's aphasic individual, noted that the Wernicke's patient made many more errors in speech than writing ( 39 versus 18) while the ir Broca's patient made more errors in writing than in speech ( 40 versus 14 ).

Smith (1971) observed writing would be the last modallty to recover even when the Individual became 
functional orally. Keenan (1971) found writing lmpalrment to be a highly sensitive indicator of aphasic involvement In mild aphasia.

Writing errors increase as less frequently used words are at tempted (Bricker, Schuell and Jenkins, 1964). Spelling errors increase as word length increases (Rubin and Bollinger, 1983; Friedericl, Schoenele, and Goodglass, $1981)$ and anticipating letters tends to increase error rate (Rubin and Bollinger, 1983). Frederici et al. (1981) found most errors occurred in the middle position of words, with greater accuracy in the Initial and final positons.

Studies comparing error types in oral and written expression generally find that types of aphasic written errors will correspond to types of their oral errors, al though impaired writing wlll generally be less complex than the pattern of verbal expression (Goodglass and Hunter, 1970; Ulatowska, Hildebrand, and Haynes, 1978)

Ulatowska, Baker, and Stern (1979) examined two written samples from twenty-five aphasic individuals. Subjects had mild to severe aphasia, were all in language treatment, and Included chlldren and older adults. The most common error was omission of auxillary verbs. Other errors included lnabllity to shift from past to present tense, omission of articles, general omission of prepositions and infrequent substitutions. Few semantic errors were found, and those that did occur involved substitutions within the same semantlc category. The 
researchers stated that spelling errors were relatively infrequent (about 1 percent of the total sample). Primary errors reportedly involved grammatic functions more often than semantic functions and most disruptions were rule based disorders. Of the entire number of samples, 25 percent were totally correct.

Ulatowska, Hildebrand and Haynes (1978) compared spoken and written language of a group of mildly aphasic individuals to an equal number of normal controls. A number of similarities were noted between the aphasic patients and controls, including: 1) writing reflected speech in the length of $T$ unlts (grammatical phrases); 2) isolated sentences were shorter than narrative sentences for both speech and writing; 3) spoken language contained more correct $T$ units than written samples; and 4) patterns of errors were similar in writing and speech. There were a number of differences between aphasic subjects and controls: 1) the aphasic subjects made more preposition and semantic errors in spoken and written language, but especially in written samples; 2) complexity of $T$ units, especially In the written samples, was decreased for aphasic individuals; and 3 ) aphas lc individuals needed more time for spoken and written language.

Goodglass and Hunter (1970) analyzed samples of spontaneous written and spoken responses to picture stimulus by a Wernicke's and a Broca's aphasic patient. Samples showed the same contrasting features in both modes 
of expression. Both subjects produced longer grammatlcal phrases in speech than in writing, and the length of grammatlc utterances between Broca's and Wernlcke's subjects was not slgnificant, though the Wernicke's patient had longer expressions in both speech and writing. Both patients were found to be almost agraphic in the early, most severe stage of the dlsorder; however, as they began to recover speech, and constrasting features of their oral language became evident, the subjects displayed parallel changes in wrlting ability. The Wernlcke's patient used a number of non-picturable nouns repetitiously in his speech, but they later dropped out of his writing. The Broca's patient had a much smaller proportion of non-plcturable nouns. Both patients made more explicit referential statements in writing than in speech. Both patlents omltted articles, verbs, copulatives, and objects of verbs, and used inflectional endings on nouns and verbs. Subject pronouns were not in accordance with subject nouns ("The man she won't go") in the speech and writing of the Broca's aphasic individual. Omission of small grammatic words and inflections occurred more frequently in the welting of the Broca's aphasic subject and more frequently in the speech of the Wernicke's aphasic subject.

Wapner and Gardner (1979) evaluated the spelling of 31 patlents who had been classlfied as "anterlor" or "posterior" aphasics. These authors concluded that overall spelling performance tended to be conslstent with other 
linguistic abilities and the simllarity of overall profile errors suggested exsistence of an approach to spelling common to all patients. Words misspelled by posterior aphaslcs generally resembled the target in that deletions were of an expected nature. There was an omission of letters needed for proper word pronunciation and homonyms were frequently misspelled, yet a high proportion of misspelled words sounded like the originals. The authors felt that the fluent patients may have been adopting a phoneme-grapheme strategy mapplng sounds to letters while the nonfluent patients were felt to have a sense of how things should look and a tendency to reverse letter order and leave out letters. The researchers suggest that the anterior nonfluent aphasic person with their preserved posterior zones may image words as a retrieval strategy.

\section{Remediation and Recovery of Writing}

Only a few treatment studies have addressed writing remediation in aphasia. These studies have examined the extent to which treatments or different types of treatment have a signlficant effect on graphlc expression and the extent to which adjustments in motoric features might affect accuracy (1.e.) different keyboards, different styles of writing or writing prosthesis improve written expression).

Schwartz, Nemeroff and Relss (1974) compared a group of elght aphaslc Individuals who recelved mult l-modal ity 
treatment to a group of aphasic persons whose intervention included alphabet writing, written picture naming, and writing to dictation. No significant differences were found between the two groups on the post test score comparisons. However, the experimental group did demonstrate a significantly greater degree of improvement between pre and post test scores. Plzzamiglio and Roberts (1967) designed a program in which patients completed an incomplete phrase using a teaching machine with a keyboard. There was no Indication that abllity to successfully complete these tasks transferred to manual writing or prevlously untaught stimulus words. Sarno, Silverman and Sands (1970) studied programmed treatment using a "language master" stimuli that included partially drawn geometic forms, and fllling in letters, words, and copylng. Post test scores in this study indicated no signiflcant differences for either the experimental group or the comparison group (treated with a nonprogrammed approach). Seron, Deloche, Moulard and Rousselle (1980) used a program to treat five patients with agraphla. Individual treatment programs were deslgned following baseline assessments. Improvement felt to be subsequent to treatment was noted in 4 of 5 patients. The patients who improved Increased their ability to correctly type stlmulus words and this appeared to carry over to manual writing. There was also evidence of generalization to words not included in treatment.

Rubin and Bollinger (1983) conducted a pilot study 
with elght aphaslc patlents using a small-step computerlzed program for spelling. Subjects ranged from 24 to 149 months post onset. All patients progressed beyond entry level and there were slgniflcant differences between preand post-test spelling scores.

Boone and Friedman (1976) analyzed data from 30 adult aphaslc subjects who were asked to write to dictation using both cursive and manuscript writing. The authors concluded that nelther writing style effectively improved graphic ablitty; however, some individuals increased writing proficiency with one or the other method.

Three right hemiplegic global aphasic patients who were agraphic with their unimpaired left hand, were provided a prosthetic device which allowed them to use the ir right hand using the prosthesis when they were unable to write with their left hand (Brown, Leader and Blum, 1983). The researchers postulated that a preliminary, subconscious or preprocessing stage of language was reached with the right hand whlch facilitated writing ability.

Few recovery studies of aphasic individuals describe level of function at regular intervals from onset to recovery (Davis, 1983). Even fewer recovery studies describe relative impairment of oral production, verbal comprehension, reading and writing. Some of those studies found in the literature follow.

Basso, Capitanl and Zanoblo (1982) analyzed 250 rehabilitated and 138 non-rehabilitated aphasic individuals 
to determine the relationship of recovery between four language modalities (verbal expression, auditory comprehension, reading and writing). The authors sought to determine if recovery of one language modality was linked with recovery of the other three. The results indicated that, among the rehabilitated patients recovery of aural and written comprehension and expression were always linked, while in non-rehabilitated patients, recovery of comprehension was not associated with recovery of oral expression, reading and writing. Kertesz (1979) observed 20 aphasic patients and reported that most improvement in reading and writing impairments occurred in the first three months after onset. This was consistent for each syndrome, except globally aphasic individuals who did not demonstrate recovery of writing during the first year after onset. Smith (1971) observed that writing in 78 aphasic Individuals examined at 22 months post onset, was more severely deficient than speech, reading, or comprehension. This was true of hemiplegic as well as nonhemlplegic aphasic Individuals.

Kenin and Swisher (1972) tested 15 aphasic patients soon after onset and again 6-12 weeks post onset. In the intervening time, the patients received language treatment. Test-retest scores indicated written sentence repetition, auditory and visual recognition of nouns and sentences and visual naming improved in sentence copying. Some patients improved in writing object names and orally producing 
sentences.

Porch (1981) reported that in a large random sample of aphasic individuals the highest mean number of correct responses occurred in gestural ability, followed by verbal and graphic correct responses. He reported this general pattern of modality ranking holds true during the course of recovery while being treated.

Generally, available cross-modality studies agree that during recovery, comprehension (auditory and reading) improves more and is relatively better preserved compared to production (oral and especially written production) (Butfield and Zangw111, 1946; Darley, 1982; Kenin and Swisher, 1972; Porch, 1981).

\section{Summary}

Aphasia is a disturbance of language processes brought on by damage to areas of the brain involved in speakling, wrlting, listenling and reading functlons. There is a degree of variation among aphasic persons in the nature of the Ir verbal disturbances relative to the overall degree of impalrment displayed and the characteristics of their speech, comprehension and writing behaviors. Aphasia has been classlfled on the basls of these disturbances (Goodglass and Kaplan, 1972a), though some aphaslologists prefer to consider the relative similarities rather than differences among aphasic persons when discussing the nature of the disorder. 
One frequently applied system of aphasla classffication divides patients into fluent and nonfluent types based upon speech output and the relative degree of comprehension impairment. Persons with fluent aphasia would be predicted to have fluently produced noncontentive paraphasic or anomic speech output. Nonfluent persons would be predicted to generally have telegraphic, laborious speech production marked by a higher incidence of contentive words (nouns) and a relative lack of functor words (e.g. articles, adjectives, adverbs) (Goodglass and Kaplan, 1972a).

Recovery studies find written language to lag behind other modalities. Writing is the most severely impaired modality; its recovery effects appear later and reach a less functional range than oral language, reading and comprehension (Duffy and Ulrich, 1976; Smith, 1971). Several areas of controversy and methodologic concerns arlse from the literature with respect to graphic performances of aphasic persons. Research methodologies have involved either narrative writing or single word writing. A broad analysis of not only linguistic parameters but also motoric features in aphasic writing has not been made. Sex, handedness and hand used for writing are factors almost completely ignored in the exsisting literature. Few studies have excluded subjects with either traumatic injurles or neoplasms. Thus the potential for confounding cognltive deflclts from multiple areas of brain 
dysfunction have not always been controlled. Theoretical statements about differences between how fluent and nonfluent aphasic persons approach the task of writing have typically come from studies of as few as one or two subjects (Goodglass and Hunter, 1970). Finally, findings regarding the narrative and sentence writing output of aphasic persons come from minimally impalred subjects (Keenan, 1979; Ulatowska, Hildebrand and Haynes, 1978) whlle findings regarding single word output come from subjects that are more severely impaired (Bub and Kertesz, 1982; Goodglass and Hunter, 1970; Hier and Mohr, 1977), or globally aphasic (Mohr et al., 1973). This literature leaves questions to be answered as to whether or not fluent and nonfluent aphasic persons perform writing tasks with more differences than similarities in the type and frequencles of their errors, and, if differences exist are they more apparent in the early rather than later stages of recovery? An analysis of a broad range of graphic performance areas, examined over time at comparable intervals with groups of subjects matched for etlology, age, sex, aphasia severity and use of their preferred or nonpreferred hands for writing, would provide information currently lacking in research literature related to writing and aphasia. 


\section{CHAPTER III}

METHODS AND PROCEDURES

\section{Subiects}

Subjects for this study included 20 aphasic Indlviduals ranging in age from 52 to 65 years. All became aphasic as a result of left hemlsphere thrombotic, embollc or thrombo-embollc cerebrovascular accidents (CVA) and had previously recelved, or were recelving, speech and language treatment at the Portland Veterans Administration Medical Center. Subjects Included only persons with Overall (OA) percentile scores no lower than the 40 th percentile on the Porch Index of Communicative Ability (BICA) (Porch, 1981) at the ir inltial evaluations (approximately one month post onset). Thls criterion for participation was based on two assumptions. Individuals with overall communicative abllities at the 40 th percentlle can generally be expected to perform most graphic tasks on the PICA. Furthermore, these individuals usually achleve at least a minimally functional level of oral language recovery, though they may or may not achleve functional writing recovery. The subjects' Inttial BICA Overall percentile scores ranged from 43 to 78 percentile for the nonfluent group, and 44 to 80 percentile for the fluent group. The mean Overall 
percentile was 57.4 for both groups. The mean age for the fluent group was 59.5 and for the nonfluent group 59.1 . Tables I and II summarlze the subject characterlstics, including age at the time of Initial assessment, date of CVA onset, testing dates, Overall PICA percentile scores at each testing date, a notation of handedness and the hand used for writing during testing.

Subjects were divided into two groups. Group I consisted of 10 subjects with nonfluent aphasic characteristics and Group II consisted of 10 subjects with fluent aphasia. Determination of group assignment for this study was made by a staff speech-language pathologist based on: 1) description of spontaneous speech and comprehension abilities; 2) performance profiles from the Boston Diagnostic Aphasia Examination (BDAE) (Goodglass and Kaplan, 1972b) and/or The Western Aphasia Battery (WAB)(Kertesz, 1980); and 3) the diagnosis of aphasia type made by the staff speech-language pathologlst providing language treatment as stated in the subjects' clinical records.

In addition to the two experimental groups, a comparison sample from 5 non-neurologlcally lmpaired individuals, with age ranges corresponding to those of the experlmental group were also gathered. The mean age of the non-lmpalred group was 55.6. Thls group had no hlstory of nervous system disease. 
TABLE I

CHARACTERISTICS OF FLUENT

APHASIC SUBJECTS

\begin{tabular}{|c|c|c|c|c|c|c|c|}
\hline $\begin{array}{c}\text { SUBJECT } \\
\text { ID }\end{array}$ & $A G E$ & ONSET & $\begin{array}{l}\text { TEST } \\
\text { DATE }\end{array}$ & $\begin{array}{l}\text { OA } \\
\text { SCORE }\end{array}$ & $\begin{array}{l}\text { WEEKS } \\
\text { POST }\end{array}$ & $\begin{array}{l}\text { HAND } \\
\text { PREF }\end{array}$ & $\begin{array}{l}\text { HAND } \\
\text { USED }\end{array}$ \\
\hline 8 & 62 & $12 / 25 / 80$ & $\begin{array}{l}1 / 22 / 81 \\
3 / 3 / 81 \\
6 / 10 / 81\end{array}$ & $\begin{array}{l}61 \\
80 \\
91\end{array}$ & $\begin{array}{r}4 \\
9 \\
22\end{array}$ & $\mathbf{R}$ & $\mathrm{R}$ \\
\hline 5 & 59 & $2 / 21 / 82$ & $\begin{array}{l}3 / 12 / 82 \\
6 / 4 / 82 \\
8 / 27 / 82\end{array}$ & $\begin{array}{l}80 \\
94 \\
92\end{array}$ & $\begin{array}{r}3 \\
14 \\
25\end{array}$ & $\mathrm{R}$ & $\mathbf{R}$ \\
\hline 4 & 62 & $9 / 17 / 81$ & $\begin{array}{r}11 / 9 / 81 \\
12 / 21 / 81 \\
3 / 16 / 82\end{array}$ & $\begin{array}{l}51 \\
52 \\
66\end{array}$ & $\begin{array}{r}7 \\
14 \\
26\end{array}$ & $\mathbf{R}$ & L \\
\hline 24 & 61 & $10 / 27 / 82$ & $\begin{array}{r}12 / 20 / 83 \\
3 / 9 / 83 \\
6 / 7 / 83\end{array}$ & $\begin{array}{l}64 \\
70 \\
86\end{array}$ & $\begin{array}{r}7 \\
12 \\
24\end{array}$ & $\mathbf{R}$ & $\mathrm{R}$ \\
\hline 15 & 56 & $12 / 28 / 79$ & $\begin{array}{l}1 / 22 / 80 \\
3 / 03 / 80 \\
7 / 12 / 80\end{array}$ & $\begin{array}{l}77 \\
87 \\
93\end{array}$ & $\begin{array}{r}4 \\
9 \\
27\end{array}$ & $\mathrm{R}$ & $\mathrm{R}$ \\
\hline 14 & 56 & $2 / 24 / 73$ & $\begin{array}{r}3 / 26 / 80 \\
5 / 30 / 73 \\
11 / 28 / 73\end{array}$ & $\begin{array}{l}47 \\
58 \\
65\end{array}$ & $\begin{array}{r}4 \\
13 \\
36\end{array}$ & $\mathbf{R}$ & $\mathbf{R}$ \\
\hline 2 & 64 & $8 / 28 / 78$ & $\begin{array}{r}19 / 19 / 78 \\
11 / 29 / 78 \\
7 / 5 / 79\end{array}$ & $\begin{array}{l}46 \\
65 \\
71\end{array}$ & $\begin{array}{l}7 \\
12 \\
40\end{array}$ & $\mathrm{R}$ & $L$ \\
\hline 25 & 55 & $7 / 30 / 72$ & $\begin{array}{r}9 / 5 / 72 \\
10 / 26 / 72 \\
1 / 15 / 73\end{array}$ & $\begin{array}{l}44 \\
63 \\
59\end{array}$ & $\begin{array}{r}5 \\
12 \\
21\end{array}$ & $\mathrm{R}$ & $L$ \\
\hline 21 & 63 & $10 / 12 / 77$ & $\begin{array}{r}11 / 15 / 77 \\
1 / 30 / 78 \\
3 / 27 / 78\end{array}$ & $\begin{array}{l}73 \\
84 \\
76\end{array}$ & $\begin{array}{r}4 \\
14 \\
22\end{array}$ & $\mathrm{R}$ & $\mathbf{R}$ \\
\hline 7 & 57 & $6 / 11 / 80$ & $\begin{array}{r}8 / 15 / 80 \\
11 / 12 / 80 \\
4 / 27 / 81\end{array}$ & $\begin{array}{l}44 \\
68 \\
83\end{array}$ & $\begin{array}{r}8 \\
20 \\
40\end{array}$ & $\mathbf{R}$ & $\mathbf{R}$ \\
\hline
\end{tabular}


TABLE II

CHARACTERISTICS OF NONFLUENT

APHASIC SUBJECTS

\begin{tabular}{|c|c|c|c|c|c|c|c|}
\hline $\begin{array}{c}\text { SUBJECTS } \\
\text { ID. }\end{array}$ & AGE & ONSET & $\begin{array}{l}\text { TEST } \\
\text { DATE }\end{array}$ & $\begin{array}{l}\text { OA } \\
\text { SCORE }\end{array}$ & $\begin{array}{l}\text { WEEKS } \\
\text { POST }\end{array}$ & $\begin{array}{l}\text { HAND } \\
\text { PREF }\end{array}$ & $\begin{array}{l}\text { HAND } \\
\text { USED }\end{array}$ \\
\hline 11 & 56 & $9 / 19 / 74$ & $\begin{array}{r}10 / 22 / 74 \\
12 / 19 / 74 \\
3 / 75 / 75\end{array}$ & $\begin{array}{l}78 \\
88 \\
90\end{array}$ & $\begin{array}{r}4 \\
12 \\
24\end{array}$ & $R$ & $\mathrm{R}$ \\
\hline 13 & 52 & $7 / 12 / 73$ & $\begin{array}{r}8 / 14 / 73 \\
10 / 18 / 73 \\
1 / 11 / 74\end{array}$ & $\begin{array}{l}57 \\
77 \\
86\end{array}$ & $\begin{array}{r}4 \\
13 \\
24\end{array}$ & $R$ & L \\
\hline 19 & 59 & $12 / 25 / 74$ & $\begin{array}{l}2 / 7 / 75 \\
4 / 7 / 74 \\
6 / 24 / 75\end{array}$ & $\begin{array}{l}44 \\
49 \\
60\end{array}$ & $\begin{array}{r}6 \\
14 \\
24\end{array}$ & $R$ & $\mathrm{R}$ \\
\hline 1 & 64 & $8 / 15 / 77$ & $\begin{array}{r}9 / 15 / 77 \\
11 / 17 / 77 \\
2 / 14 / 78\end{array}$ & $\begin{array}{l}71 \\
87 \\
91\end{array}$ & $\begin{array}{r}4 \\
12 \\
24\end{array}$ & $\mathbf{R}$ & $L$ \\
\hline 10 & 60 & $6 / 7 / 77$ & $\begin{array}{l}8 / 1 / 77 \\
9 / 29 / 77 \\
2 / 8 / 78\end{array}$ & $\begin{array}{l}45 \\
72 \\
90\end{array}$ & $\begin{array}{r}7 \\
15 \\
32\end{array}$ & $\mathbf{R}$ & $\mathrm{R}$ \\
\hline 17 & 63 & $6 / 11 / 80$ & $\begin{array}{r}7 / 1 / 80 \\
9 / 15 / 80 \\
12 / 10 / 80\end{array}$ & $\begin{array}{l}62 \\
74 \\
78\end{array}$ & $\begin{array}{r}3 \\
12 \\
24\end{array}$ & $\mathbf{R}$ & $L$ \\
\hline 23 & 58 & $8 / 14 / 79$ & $\begin{array}{r}10 / 10 / 79 \\
1 / 16 / 80 \\
2 / 13 / 80\end{array}$ & $\begin{array}{l}62 \\
72 \\
70\end{array}$ & $\begin{array}{r}8 \\
20 \\
24\end{array}$ & $\mathbf{R}$ & $\mathrm{R}$ \\
\hline 16 & 65 & $12 / 20 / 74$ & $\begin{array}{l}1 / 17 / 75 \\
3 / 19 / 75 \\
8 / 14 / 75\end{array}$ & $\begin{array}{l}43 \\
76 \\
81\end{array}$ & $\begin{array}{r}4 \\
12 \\
32\end{array}$ & $\mathrm{R}$ & $R$ \\
\hline 6 & 60 & $5 / 30 / 75$ & $\begin{array}{r}6 / 30 / 75 \\
8 / 26 / 75 \\
12 / 4 / 75\end{array}$ & $\begin{array}{l}54 \\
81 \\
79\end{array}$ & $\begin{array}{r}4 \\
12 \\
25\end{array}$ & $\mathrm{R}$ & $R$ \\
\hline 26 & 54 & $3 / 16 / 78$ & $\begin{array}{r}5 / 5 / 78 \\
7 / 14 / 78 \\
10 / 4 / 78\end{array}$ & $\begin{array}{l}58 \\
90 \\
90\end{array}$ & $\begin{array}{r}8 \\
16 \\
26\end{array}$ & $R$ & $R$ \\
\hline
\end{tabular}




\section{Procedures}

\section{Graphic Samoles}

Graphic samples of sentence writing, writing single words, and copying words were gathered retrospectively from PICA subtests that had been adminlstered at three intervals of recovery. Xeroxed copies of the BICA graphic subtest $A$ through $E$ were made for later analys ls. All testing was administered in the standard manner outlined by Porch (1981). Test procedures with the PICA includes administration of 18 subtests, including: 4 verbal, 8 gestural and 6 graphic subtests. Administration procedures for the graphlc subtests include placing ten common objects (toothbrush, clgarette, pen, knife, fork, quarter, pencll, matches, key and combs in front of the subject and eliciting written responses to the subtest instructions. Appendix A provides a description of the instructions given to subjects prior to each of the graphic subtests.

Graphic Subtests A, B, C, D, and E provided the samples for analysis. Subtest A provided a sample of the subjects' abllities to write ten short declarative sentences describing how one uses each of the stimulus objects. Subtest B provided a sample of the subjects' abllities to write the name of the ten items without assistance from the examiner. Subtest $C$ provided a sample of the subjects' abllitles to write the name of each of ten Items after the name of each 1 tem was verbally dictated by 
the examiner. Subtest D provided a sample of the subjects' abilities to write the name of each of the objects after the examiner spelled the word orally. Subtest $E$ provided a sample of the subjects' abilities to copy the name of each object from the printed words provided on the test form.

Three sets of samples were gathered from PICAs

administered to each subject in Group I and II at approximately one to two months, three to five months and six to twelve months post cerebrovascular accident. Thus there were 60 samples for each graphic subtest, 3 samples for each of the 20 subjects in the two groups. One set of samples from the reference group of normal (nonneurologically impaired) persons was gathered by administering the entire PICA to these subjects. Subtest samples were numerically coded for anonymity and then randomized across time and subjects for later analysis.

\section{Inter-iudae Reliability of Proposed Procedures}

Proposed analysis procedures and criteria initially were developed by this investigator and a speech-language pathologist colleague. Inter-judge reliability for these guidelines was determined prior to the analys is of the experlmental samples (Appendix B). Four judges, Including this Investigator, met to discuss, evaluate and further develop the assessment procedures and criteria to be used for subsequent analysis of the graphic samples. These reviewers were four speech-language pathologists, including 
one doctoral level clinician and three master's level clinicians in speech-language pathology.

Twenty sample subtests were independently analyzed by these reviewers using the proposed definttional guldelines. The reviewers' scores for these samples were then compared as described below. A criterion of agreement for the reviewers' scores was established and only definltional criterla guldelines with high inter-judge rellabillity were included in the later experimental analysis of the samples. High inter-judge rellabllity was considered to occur whenever three of four revlewers' scores were the same, or variance was no greater than 1.5 based on item-by-item score comparisons. Those definitions which had high agreement were used in the later analysis of the experimental samples. Any analysis criterion (or guidelines) failing to yield close inter-rater reliability was eliminated from the experimental procedures. Appendix B lists the criterla that were applied for each Subtest during the experimental analysis, based upon the outcome of the inter-judge rellabllity assessment.

\section{Data Measurement and Analys is}

This researcher examined the collected xeroxed coples of the subtest forms whlch included a total of 300 graphic subtests from the aphaslc subjects (1.e.) Subtests $A, B, C$, $D$, and $E$ taken at three time intervals from each of the 20 aphas (c subjects). Also Included in the collected samples 
were the 25 subtests samples from the normal subjects. Performances of the normal subjects were not included in the data analysis, but were used to illustrate graphically how the findings compared to normal. As a part of the intra-judge reliabllity procedures, 10 sub-test samples randomly taken from the aphasic subjects, were evaluated twice. Thus, the collected series of subtest samples included: 1) 300 subtest samples from the aphasic groups; 2) 25 subtest samples from the normal subjects; and 3) 10 randomly selected repeated samples from the aphasic group, yielding a total of 335 randomly ordered samples.

Analysis of Graphic Characteristics and Error Iypes

After interjudge reliability had been tested and those items not meeting criteria had been eliminated from the analys is procedures, the 335 subtest samples were analyzed. Each sample from a single subtest was examined across various motoric features. Linguistic features were analyzed depending upon the type of sample elicited by that subtest, l.e. sentences from Subtest $A$ were analyzed differently from the single word responses of Subtest $B$ through E (Appendix B).

\section{Subtest A}

Motoric features, as well as word types and lingulstic errors, were examined in reviewing subtest $A$, as outlined below:

A. Linguistic features 
1. The number of words that were spelled correctly, incorrectly, or unscorable in the entire subtest sample

2. The number of words attempted

3. The number of various word forms, (verbs, nouns, pronouns, adjectives, adverbs, conjunctions and prepositions)

4. The number of word forms that could not be classified.

B. Motoric features evaluated:

1. The number of sentences where $75 \%$ or more of the line was larger than $1 \mathrm{~cm}$, within $1 \mathrm{~cm}$, or less than $1 / 2 \mathrm{~cm}$

2. Whether letter style was curslve, manuscript or mixed

3. The number of lines that were tremulous (shaky), fluid or horizontal (no more than a 15 degree slant upward or downward)

4. The number of letters that were amblguous, reversed, overlapping, or marked over.

\section{Subtests $B-E$}

Motorlc features examined in Subtests $B-E$ were Identical to those descrlbed in subtest $A$.

Linguistic features of Subtests B-E were broadly categorlzed as spelling and noun characteristics, and were examined as follows: 
1. The number of words that were spelled correctly were counted. When a word was misspelled but approximated the target word, the number of letters added, deleted, subtituted or transposed were counted.

2. The number of words that were recognizable, semantlcally related, literal paraphaslas, neologisms, or perseverations were noted.

\section{Data Analys is}

Parametric statlstical analysis ( $t$-tests) was applied to those variables yielding percent or mean scores with homogeneity of variances. A nonparametric statistic Chi square was applied to those variables yielding scores lacking homogenelty of varlance. The probability level of significance of difference for the $t$-test comparisons was $p<.05$. Two talled tests were made on between group comparlsons. Between group comparisons were made on each variable across the three time intervals. Between time interval comparisons were made with the combined scores of both experimental groups considered together on all variables. 


\section{CHAPTER IV \\ RESULTS AND DISCUSSION}

\section{Results}

Fluent and Nonfluent Aphasic Group Comparisons

This study examined significant motoric and

lingulstic differences between fluent and nonfluent aphasic persons' graphic production at three intervals of recovery. The mean number of graphic responses to each variable produced by the fluent and nonfluent aphasic groups were statistically analyzed at each of the three time intervals. Appendix C contains raw data information. Only two of the variables demonstrated a statistically significant difference $(p<.05)$. These significant variables, which both occurred at Time I, were: 1) "unclassifiable", a linguistic variable occurring in Subtest $A$, "word types"; and 2) "substitution" referring to letter substitution in spelling analysis, Subtests B-E. The fluent aphasic group mean was 11.90 for unclass 1 flable words in Subtest $A$, compared to 2.70 for the nonfluent group. The fluent group also produced more letter substitutions (mean=1.94) compared to the nonfluent group (mean .96). Three other variables approached significance $(.05(p) .10)$, including 
the lingulstlc varlable "neologlsm" at IIme I, the motorlc letter execution error, "ambiguous letters" at Time II and the letter execution error "overmark" at Time III. The fluent group produced more neologisms and ambiguous letters, whlle the nonfluent group produced marked-over letters more often. See Table III for levels of signicance and group means for these varlables.

\section{Comblned Group Changes}

The second purpose of this study was to determine significant changes in graphic production of aphasic individuals over three evaluation times. The mean number of graphlc responses for the fluent and nonfluent groups were combined to analyze change over time statistically. Tables IV through IX list varlables that approached or reached a level of slgniflcance, the time at whlch these statistically slgnlficant mean number of responses occurred and direction of change for the group of twenty aphasic subjects. The t-test comparisons indicated the following motoric variables reached a level of signlficance ( $p<.05)$ durling at least one of the evaluation times: writing within 1/2-1 cm increased whlle writing smaller than $1 / 2 \mathrm{~cm}$ and larger than $1 \mathrm{~cm}$ decreased; tremorous and nonfluid writing decreased. Lingulstic varlables found to be slgniflcant for Subtests B-E during one or more of the evaluation perlods included an increase in the number of words spelled correctly, an increase in number of recognizable words, and 
TABLE III

BETWEEN GROUP COMPARISONS AT

THREE TIME INTERVALS

VARIABLE TIME GROUP MEAN SD T-VALUE $\quad$ DF $\quad$ P

Unclassif 1-

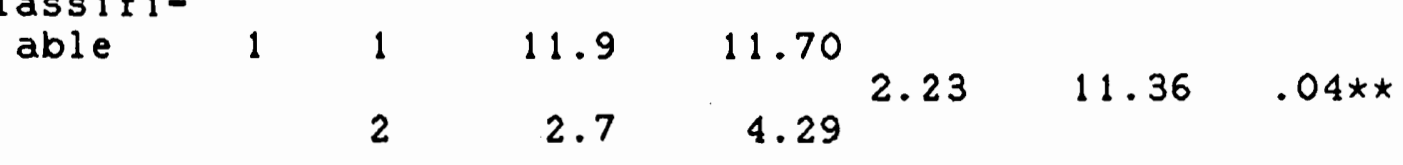

$\begin{array}{lllllll}\text { Substitution } 1 & 1 & 1.94 & 1.21 & & & \\ & 2 & 0.96 & 0.67 & & 14.00 & .04 * *\end{array}$

$\begin{array}{lllllll}\text { Neologisms } & 1 & 1 & 4.62 & 2.64 & & \\ & & 2 & 2.69 & 2.14 & & \end{array}$

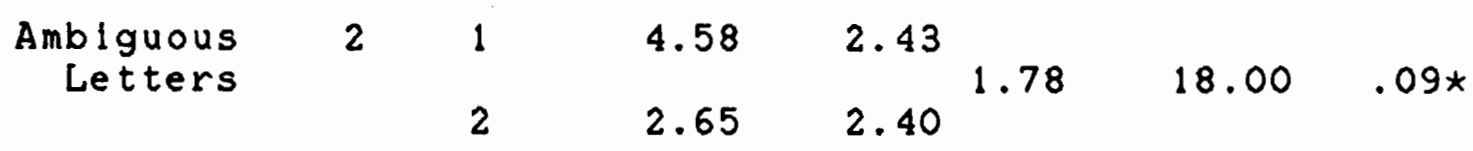

$\begin{array}{lllll}\text { Overmarking } & 3 & 1 & 1.36 & 0.99\end{array}$

$2 \quad 2.36 \quad 1.14^{-2.09} \quad 17.68 \quad .05 *$

\footnotetext{
$\star$ Trend .05-1

$\star \star p<.05$
} 
TABLE IV

BETWEEN TIME CHANGE FOR COMBINED GROUP

LINGUISTIC VARIABLES

VARIABLE TIME

Correct

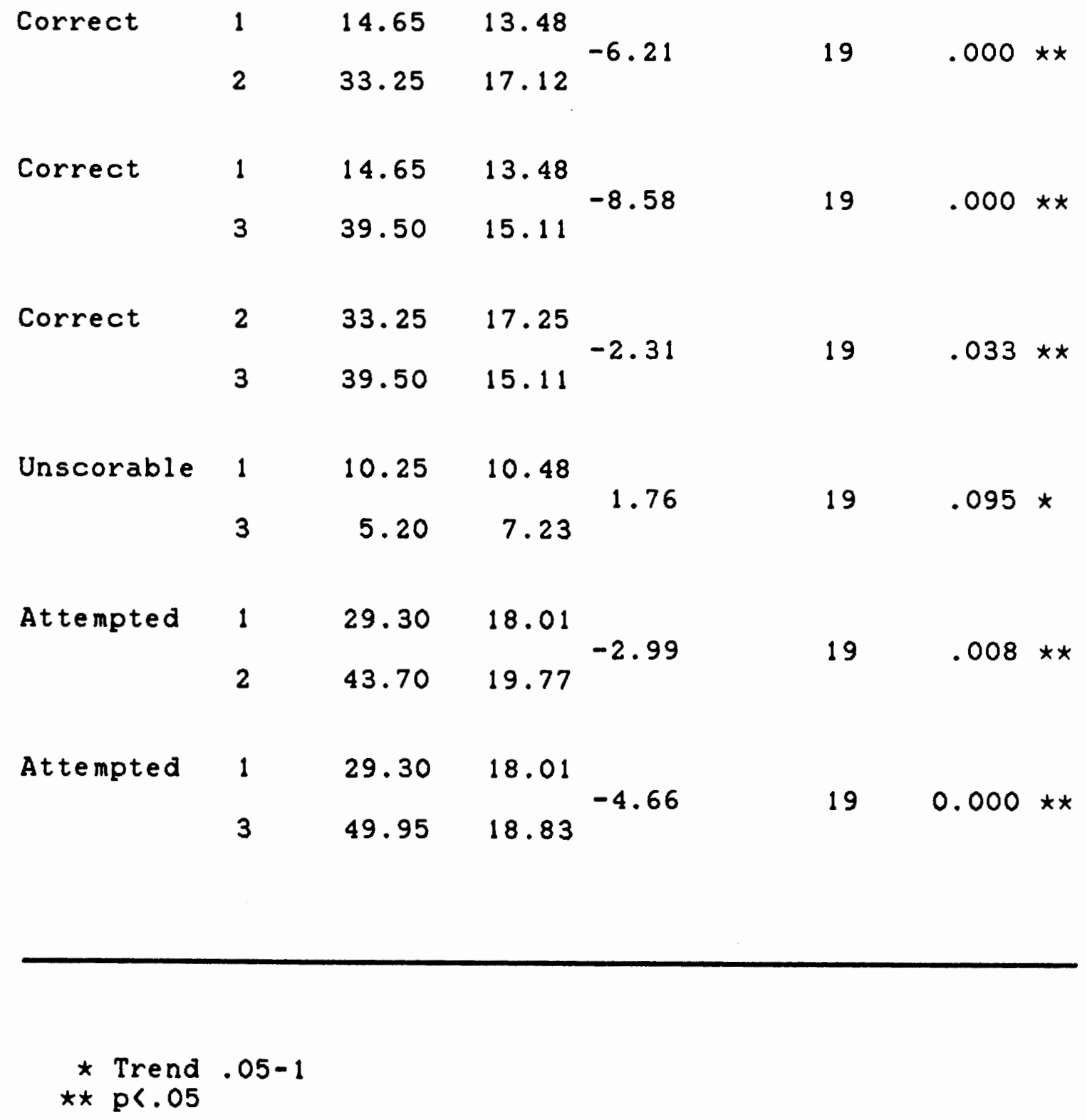

DF

$\mathbf{P}$ 
TABLE V

BETWEEN TIME CHANGE FOR COMBINED GROUP

LINGUISTIC VARIABLES

VARIABLE TIM
Spelfing. B-E

$\begin{array}{lllllll}\text { Correct } & 1 & 4.88 & 2.48 & & & \\ & 2 & 6.65 & 1.94 & -4.13 & 19 & .001 \star \star \\ \text { Correct } & 1 & 4.88 & 2.48 & & & \\ & 3 & 8.02 & 1.87 & & 19 & 0.000 \star \star \\ \text { Correct } & 2 & 6.65 & 1.94 & & & \\ & 3 & 8.02 & 1.87 & -3.85 & 19 & 0.001 \star \star\end{array}$

Linguistic, Parts of Speech

Verbs

$14.88 \quad 0.86$

$2 \quad 10.30 \quad 6.45^{-5.55}$

$190.000 \star \star$

Verbs

$14.15 \quad 3.88$

$3 \quad 11.40 \quad 4.96$

$-7.67$

19

$0.000 \star \star$

Prepos 1-

tions

1

2

3.05

4.11

$5.45^{4.05^{-2.62}}$

3.054 .11

Preposi-

$t i$ ons

1

3

$6.00 \quad 3.75$
$-3.47$

19

19

$0.016 * *$

$190.016 x x$

* Trend .05-1

$\star \star \mathrm{p}<.05$ 
TABLE VI

BETWEEN TIME CHANGE FOR COMBINED GROUP

LINGUISTIC VARIABLES

\begin{tabular}{lcccccc}
\hline VARIABLE & TIME & MEAN & SD & T-VALUE & DF & P \\
\hline Pronouns & 1 & 2.20 & 5.16 & & 19 & $0.070 *$
\end{tabular}

\begin{tabular}{|c|c|c|c|c|c|c|}
\hline Articles & $\begin{array}{l}1 \\
2\end{array}$ & $\begin{array}{l}1.70 \\
4.30\end{array}$ & $\begin{array}{l}3.26 \\
3.49\end{array}$ & -2.18 & 19 & 0.042 \\
\hline Articles & $\begin{array}{l}1 \\
3\end{array}$ & $\begin{array}{l}1.70 \\
6.20\end{array}$ & $\begin{array}{l}3.26 \\
4.61\end{array}$ & -5.18 & 19 & 0.000 \\
\hline Nouns & $\begin{array}{l}1 \\
2\end{array}$ & $\begin{array}{r}5.20 \\
11.50\end{array}$ & $\begin{array}{l}5.14 \\
5.15\end{array}$ & -5.62 & 19 & 0.000 \\
\hline Nouns & $\begin{array}{l}1 \\
3\end{array}$ & $\begin{array}{r}5.20 \\
13.30\end{array}$ & $\begin{array}{l}5.14 \\
4.88\end{array}$ & -8.86 & 19 & 0.000 \\
\hline Nouns & $\begin{array}{l}2 \\
3\end{array}$ & $\begin{array}{l}11.50 \\
13.30\end{array}$ & $\begin{array}{l}5.15 \\
4.88\end{array}$ & -2.46 & 19 & 0.000 \\
\hline
\end{tabular}

$\star$ Trend $.05-1$
$\star \star$ p $<.05$ 
TABLE VII

BETWEEN TIME CHANGE FOR COMBINED GROUP

LINGUISTIC VARIABLES

\begin{tabular}{lllllll}
\hline VARIABLE & TIME & MEAN & SD & T-VALUE & DF & P
\end{tabular}

\section{Error Types}

\begin{tabular}{|c|c|c|c|c|c|c|c|}
\hline $\begin{array}{c}\text { Recognize- } \\
\text { able }\end{array}$ & 1 & $\begin{array}{l}5.51 \\
7.66\end{array}$ & $\begin{array}{l}2.73 \\
1.94\end{array}$ & -5.16 & 19 & 0.000 & $\star \star \star$ \\
\hline $\begin{array}{c}\text { Recognize- } \\
\text { able }\end{array}$ & 1 & $\begin{array}{l}5.51 \\
8.62\end{array}$ & $\begin{array}{l}2.73 \\
1.42\end{array}$ & -5.83 & 19 & 0.000 & $\star \star *$ \\
\hline $\begin{array}{c}\text { Recognize- } \\
\text { able }\end{array}$ & 2 & $\begin{array}{l}7.66 \\
8.62\end{array}$ & $\begin{array}{l}1.94 \\
1.42\end{array}$ & -3.56 & 19 & 0.002 & $\star \star x$ \\
\hline Paraphaslas & 2 & $\begin{array}{l}1.29 \\
0.79\end{array}$ & $\begin{array}{l}0.68 \\
0.75\end{array}$ & 3.23 & 19 & 0.004 & $\star \star$ \\
\hline Neologisms & 1 & $\begin{array}{l}3.65 \\
1.15\end{array}$ & $\begin{array}{l}2.54 \\
1.14\end{array}$ & 5.83 & 19 & 0.000 & $\star \star$ \\
\hline Neologisms & 1 & $\begin{array}{l}3.65 \\
0.82\end{array}$ & $\begin{array}{l}2.54 \\
1.05\end{array}$ & 5.19 & 19 & 0.000 & \\
\hline
\end{tabular}

Persevera- 1

0.110 .20

20 . 0 .

2.47

$190.023 \star *$

Persevera- 2

$0 \quad 0$

tions

3

0.05

0.13

$-1.76$

19

$0.094 *$

* Trend .05-1

$\star \star \mathrm{p}<.05$ 
TABLE VIII

BETWEEN TIME CHANGE FOR COMBINED GROUP MOTORIC VARIABLES

\begin{tabular}{lllllll}
\hline VARIABLE & TIME & MEAN & SD & T-VALUE & DF & P
\end{tabular}

Letter Execution

\begin{tabular}{|c|c|c|c|c|c|c|c|}
\hline Larger cm & $\begin{array}{l}1 \\
2\end{array}$ & $\begin{array}{r}19.47 \\
5.42\end{array}$ & $\begin{array}{l}33.83 \\
19.16\end{array}$ & 2.17 & 19 & .043 & $\star \star$ \\
\hline Larger $\mathrm{cm}$ & 1 & $\begin{array}{r}19.47 \\
6.55\end{array}$ & $\begin{array}{l}33.83 \\
18.44\end{array}$ & 1.85 & 19 & 0.081 & $\star$ \\
\hline Within $\mathrm{cm}$ & 2 & $\begin{array}{l}63.37 \\
78.06\end{array}$ & $\begin{array}{l}36.79 \\
32.37\end{array}$ & -1.81 & 19 & 0.086 & $\star$ \\
\hline Within $\mathrm{cm}$ & 1 & $\begin{array}{l}63.37 \\
86.54\end{array}$ & $\begin{array}{l}36.79 \\
22.31\end{array}$ & -3.11 & 19 & 0.006 & $\star \star$ \\
\hline Smaller cm & 1 & $\begin{array}{r}17.05 \\
6.90\end{array}$ & $\begin{array}{l}30.08 \\
15.91\end{array}$ & 2.22 & 19 & 0.038 & $\star \star$ \\
\hline Smaller cm & 2 & $\begin{array}{r}16.51 \\
6.90\end{array}$ & $\begin{array}{l}27.16 \\
15.91\end{array}$ & 3.15 & 19 & 0.005 & \\
\hline
\end{tabular}

$\begin{aligned} \star & \text { Trend } \\ \star \star & 05-1\end{aligned}$ 
TABLE IX

BETWEEN TIME CHANGE FOR COMBINED GROUP MOTORIC VARIABLES

\begin{tabular}{lllllll}
\hline VARIABLE & TIME & MEAN & SD & T-VALUE & DF & $P$ \\
\hline
\end{tabular}

\section{Line execution}

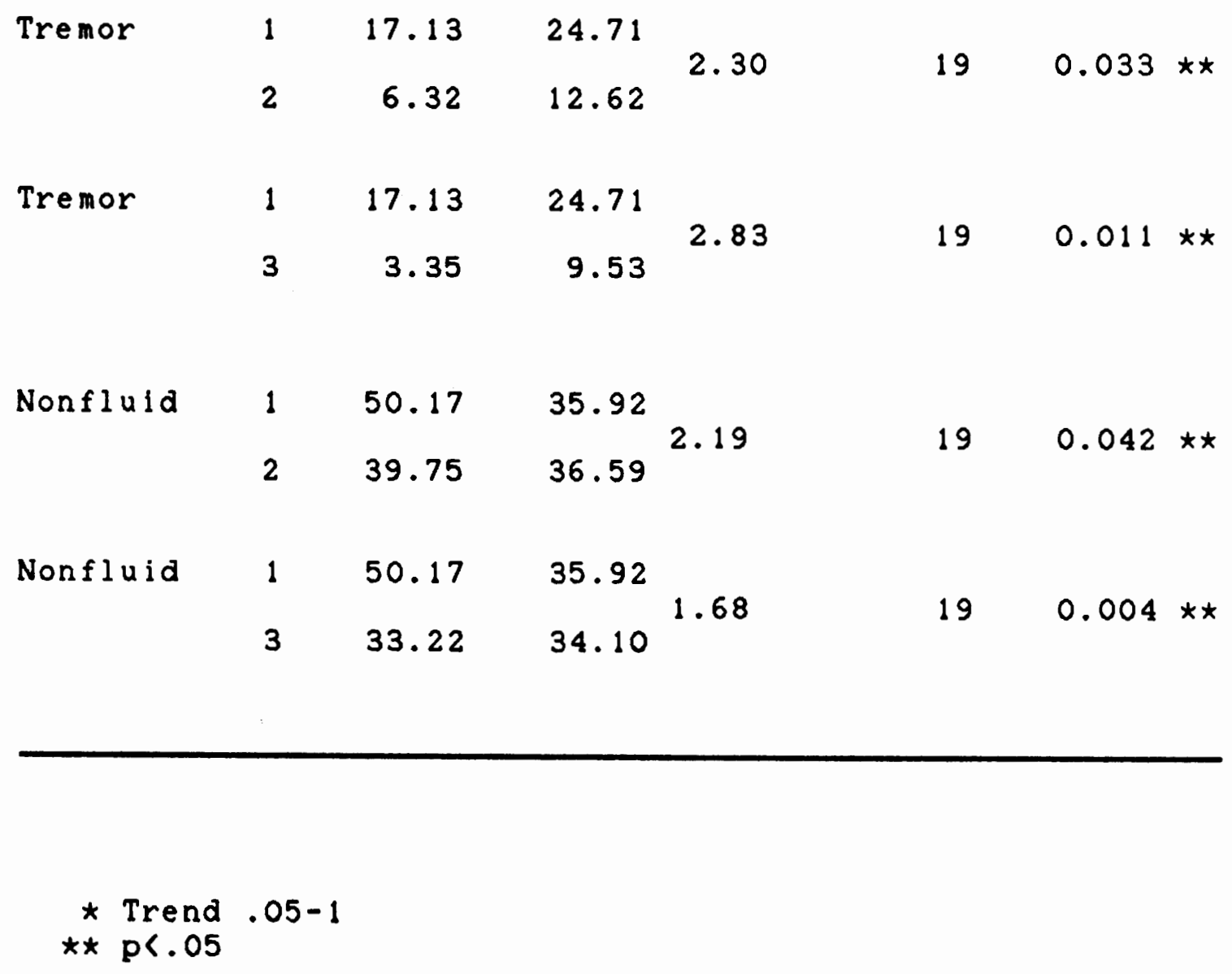


a decrease in literal paraphasias, neologlsms, and perseverations. Linguistic factors in Subtest A reaching a level of slgniflcance for the comblned fluent and nonfluent groups during at least one evaluation time included an increase in the mean number of words spelled correctly, words attempted, and recognizable words, and a decrease in unscorable words. The mean number of several parts of speech, i.e., verbs, preposititions, pronouns, articles and nouns were also found to increase slgnlficantly during at least one of the evaluation time periods. Several of the variables that reached significance also approached significance at another time. These variables included within $1 \mathrm{~cm}$, larger than $1 \mathrm{~cm}$, and perseveration. Three other variables approached but never reached signficance when the number of 1 iteral paraphaslas (Subtests B-E) and unscorable spelling words (Subtest A) decreased and the number of pronouns increased.

\section{Discussion}

Two major questions are addressed in this study: 1) Are there signiflcant motorlc and linguistic differences In the graphlc production between fluent and nonfluent persons at three intervals of recovery in response to ldentlcal test stimulus? 2) Are there signiflcant changes, over three evaluation times, in the graphic production of aphasic Individuals? The questions posed in this study are discussed separately under the topic headings of between 
group comparisons and between time comparisons.

Between Group Comparisons

Relatively little research exists which analyzes graphlc production of fluent and nonfluent individuals, yet most clinicians and researchers postulate written output will be similar in form and content to oral production (Goodglass and Hunter, 1970; Hellman, 1975; Ulatowska, Hildebrand, and Haynes, 1978). It was assumed that written responses of the fluent aphasic group in this study would be mechanlcally good, but lacking in meanlngful content words (Brookshire, 1978). Writing of fluent aphasics was expected to be abundant and unintelliglble cMarcle and Hacaen, 1979), marked with literal and verbal paraphasias (Brookshire, 1978) and neologisms (Margolin and Binder, 1984). The nonfluent group was expected to produce fewer wrltten attempts and omit functor words (Margolin and Binder, 1984) resulting in a telegraphlc style of writing (Davis, 1984). Individual written words of the nonfluent group were expected to contain transpositions, additions, and substitutions of graphemes (Marcle and Hecaen, 1979). Thls study did not demonstrate the predicted statistical differences in graphlc production between the fluent and nonfluent aphasic groups; however, there were differences between the two groups that wlll be described and might have reached statistlcal signiflcance with a 
larger study population. Although there appeared to be $f e w$ quantitative differences between the fluent and nonfluent groups at three times of evaluation, the following discussion summarizes some qualitative differences that appeared between the two groups. These observed differences may have some bearing on clinical management and expectations of the graphic production of fluent and nonfluent individuals.

\section{Linguistic Variables For Subtest A}

Word Types. Although all but one linguistic variable difference (unclassifiable) failed to reach statistical significance, Figures 1 through 7 illustrate some dlfferences that appeared between the two groups. Group responses to subtest $A$ will be compared in terms of rank order of word types, overall quantity of graphic output and a comparison of unclassiflable errors to meaningful words. The variables will be discussed in chronological order over the three evaluation periods.

At TIme I ( 1 month post onset), out of words that could be classified, verbs were the most prevelant word form for the fluent aphaslc group, followed by nouns, prepositons, articles and adjectives. Pronouns and conjunctions were negligible (Figure 1 and Table $X$ ). These results are simllar to a single case report (Ulatowska, Baker and Stern, 1979) whlch descrlbes the wrltten letters and manuscripts of a Wernlcke's aphaslc patient observed 


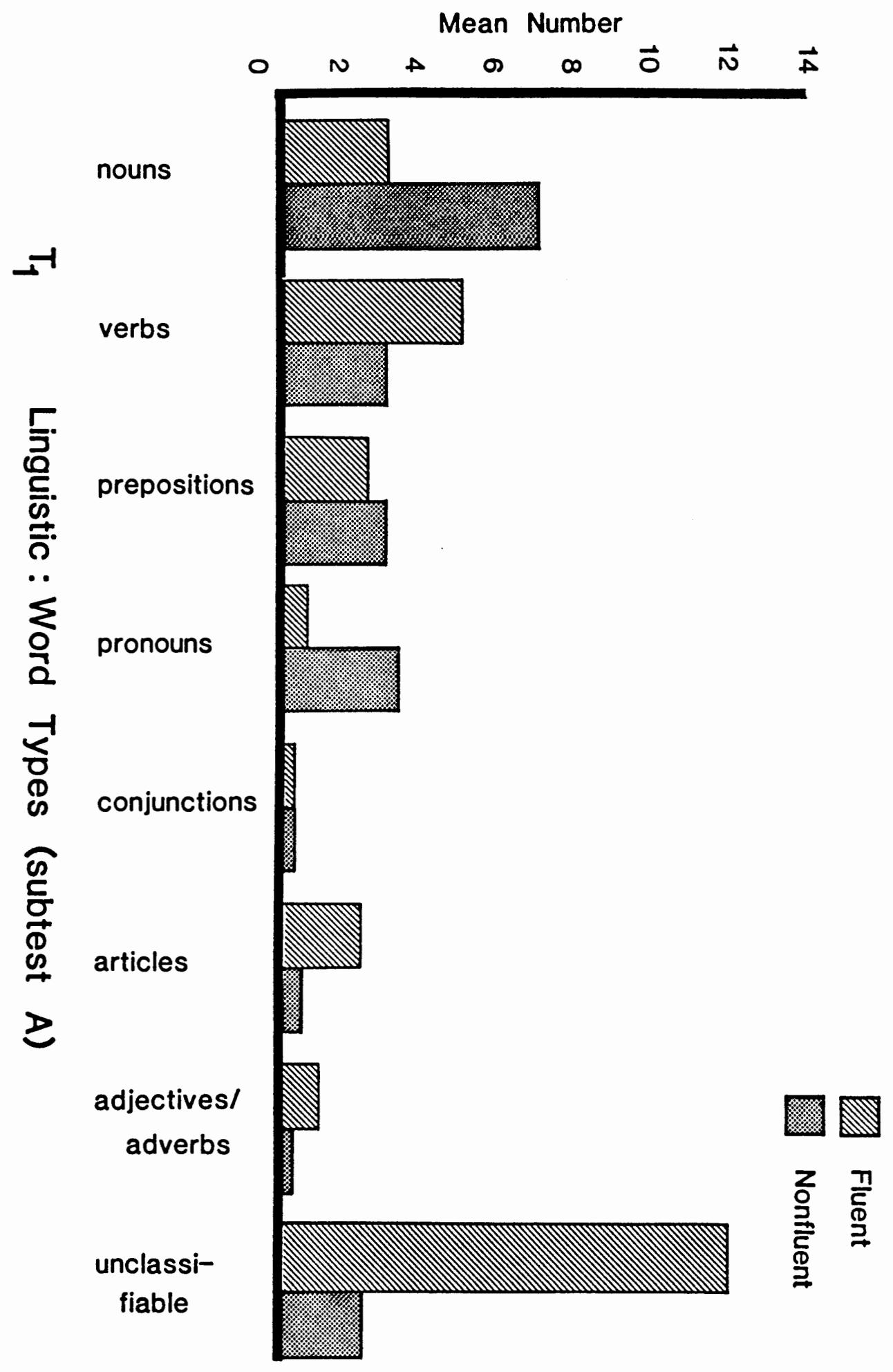

Figure 1. Comparison of fluent and nonfluent aphasic groups use of linguistic word types at Time I, Subtest A. 


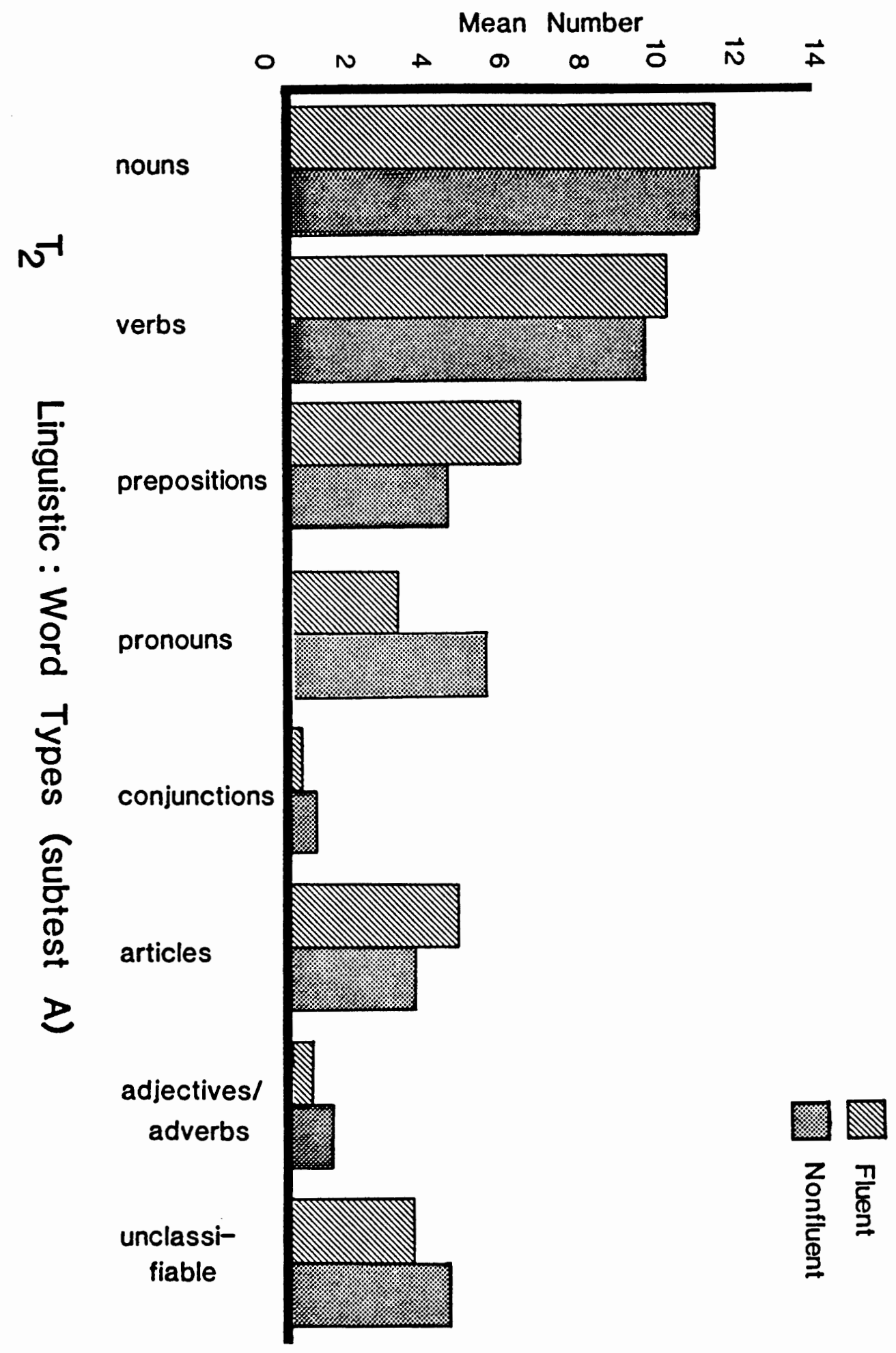

Figure 2. Comparison of fluent and nonfluent aphasic groups use of linguistic word types at Time II, Subtest A. 
Mean Number

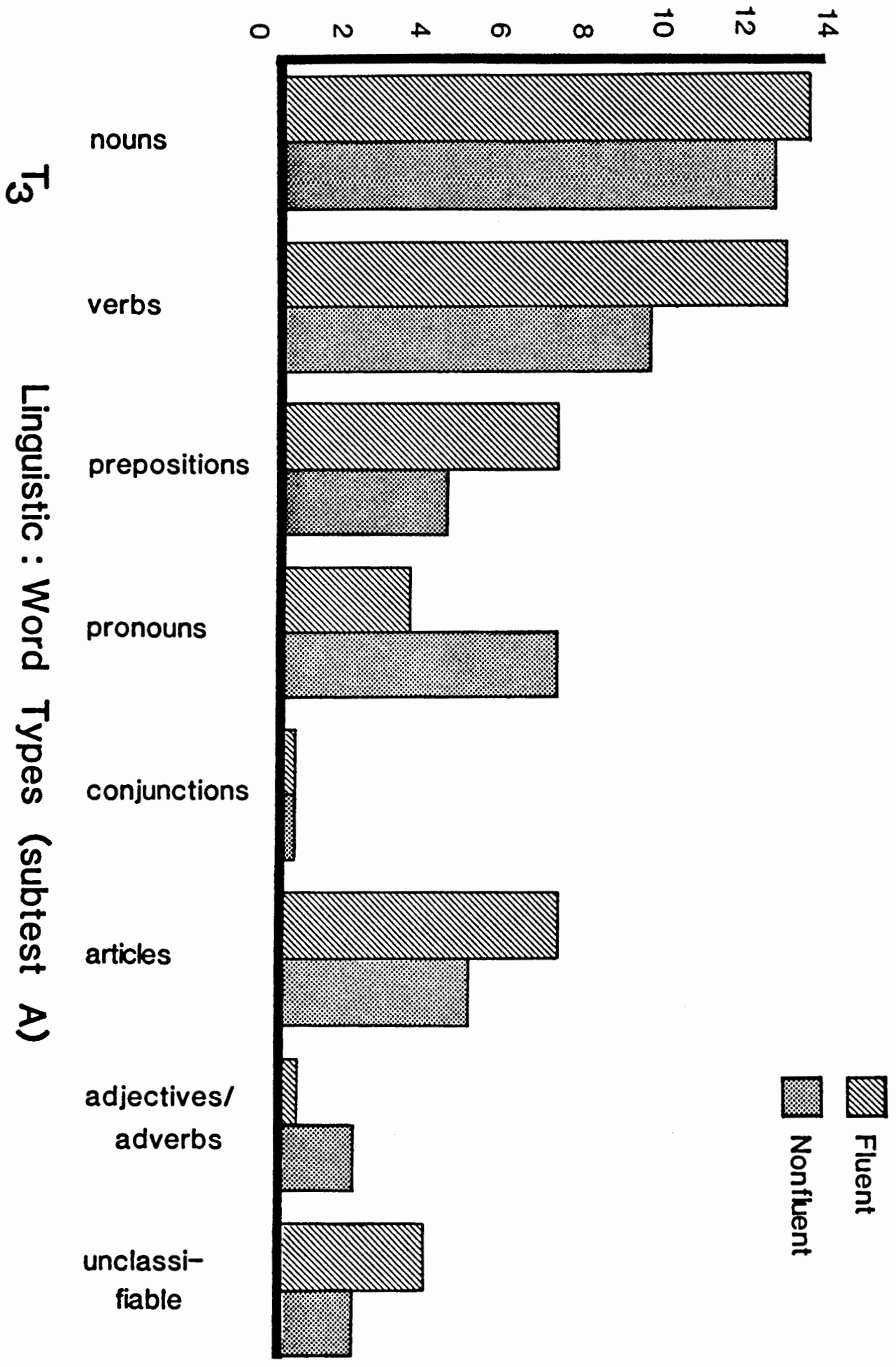

Figure 3. Comparison of fluent and nonfluent aphasic groups use of linguistic word types at Time III, Subtest A. 
Mean Number

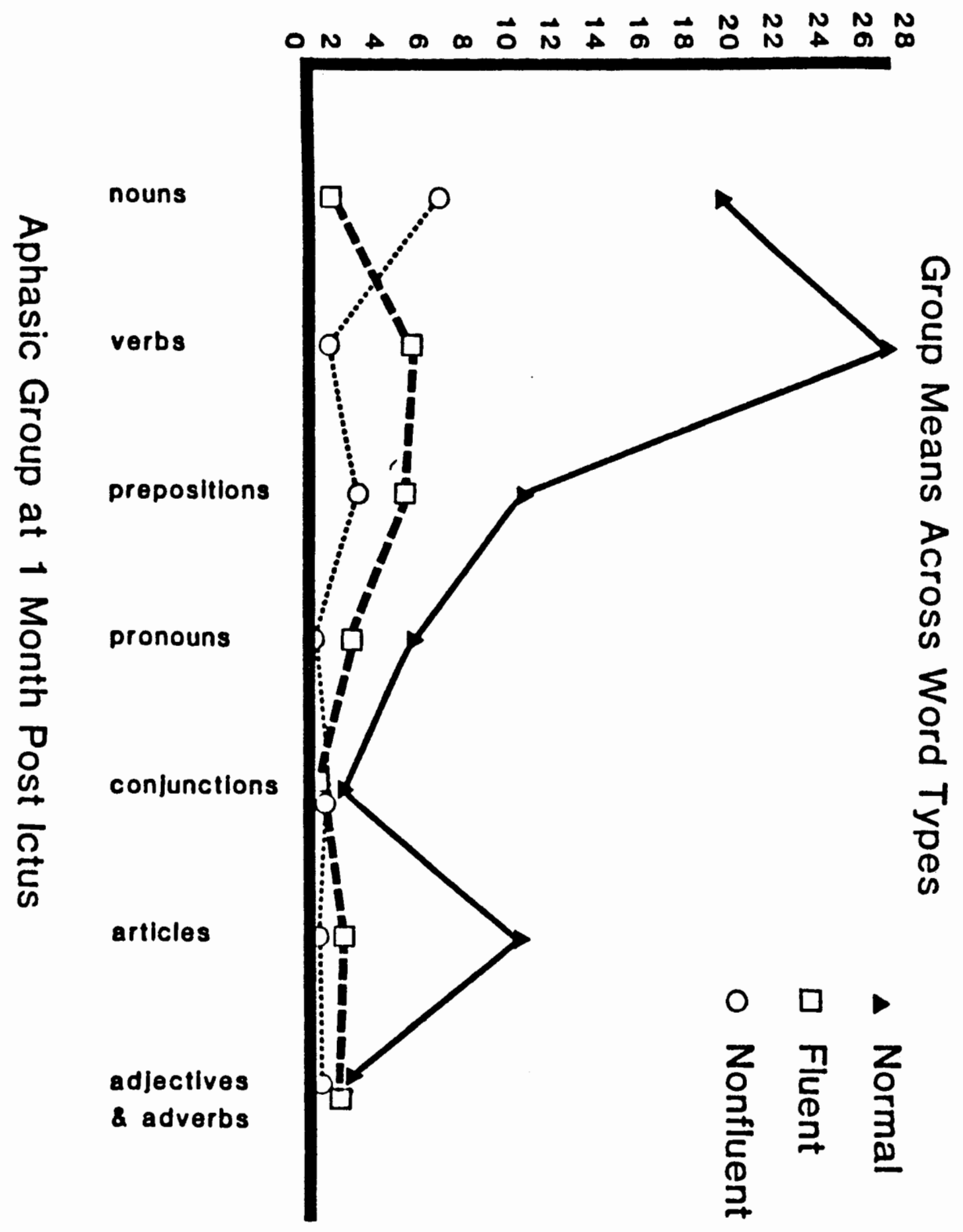

Figure 4. Comparison of fluent and nonfluent aphasic groups and normal subjects, word types, Time I. 
Mean Number

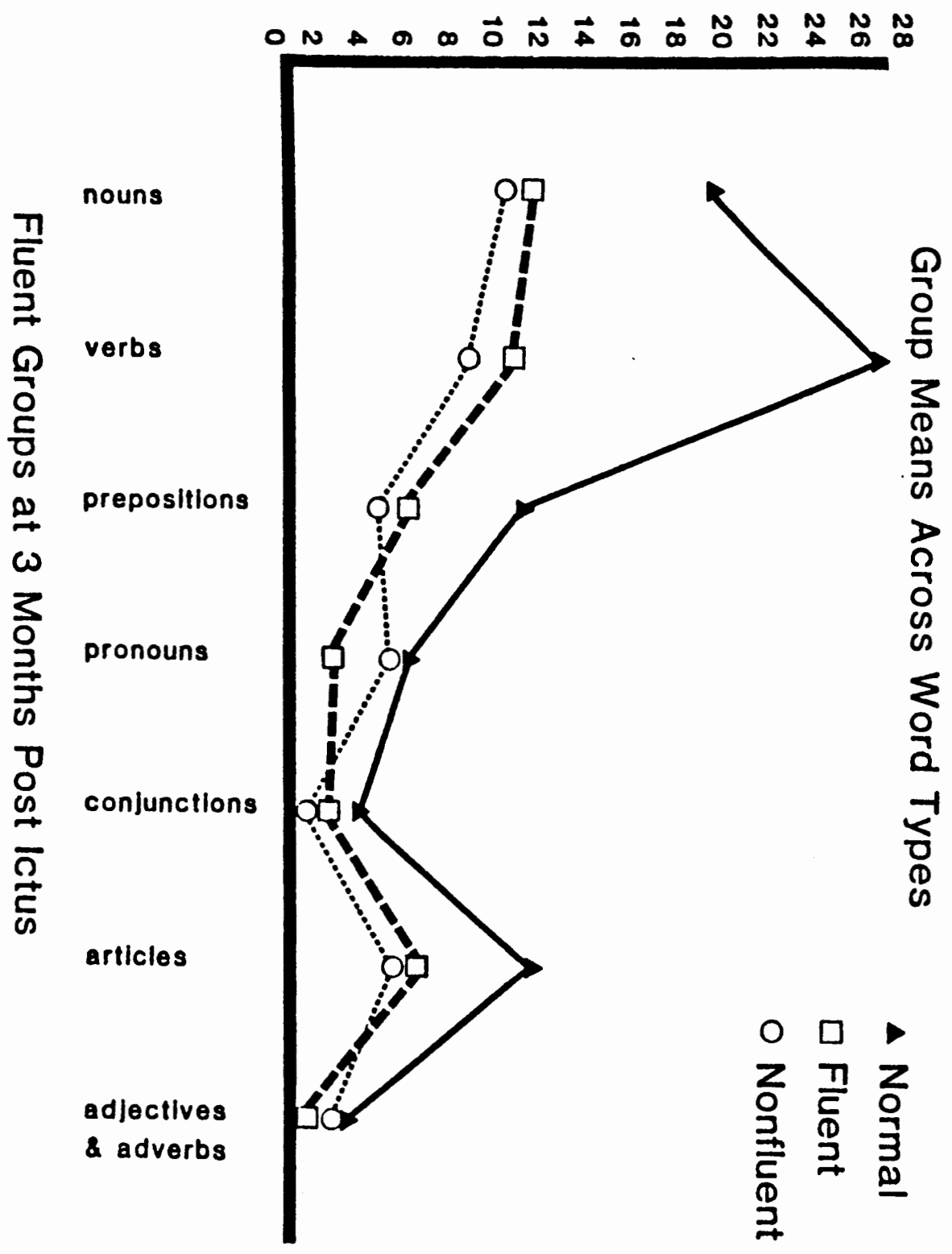

Figure 5. Comparison of fluent and nonfluent aphasic groups and normal subjects, word types, Time II. 


\section{Mean Number}

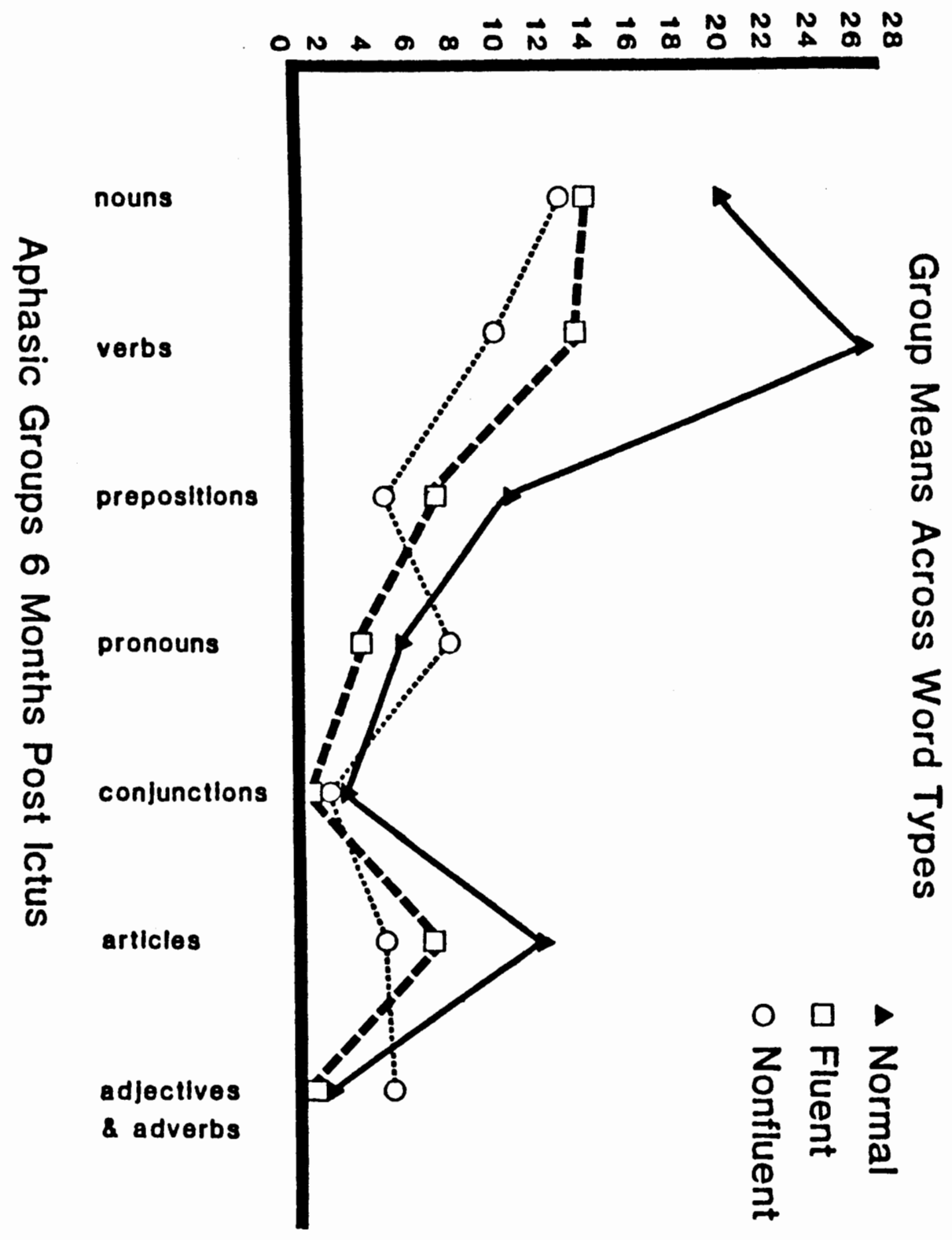

Figure 6. Comparison of fluent and nonfluent aphasic groups and normal subjects, word types, Time III. 


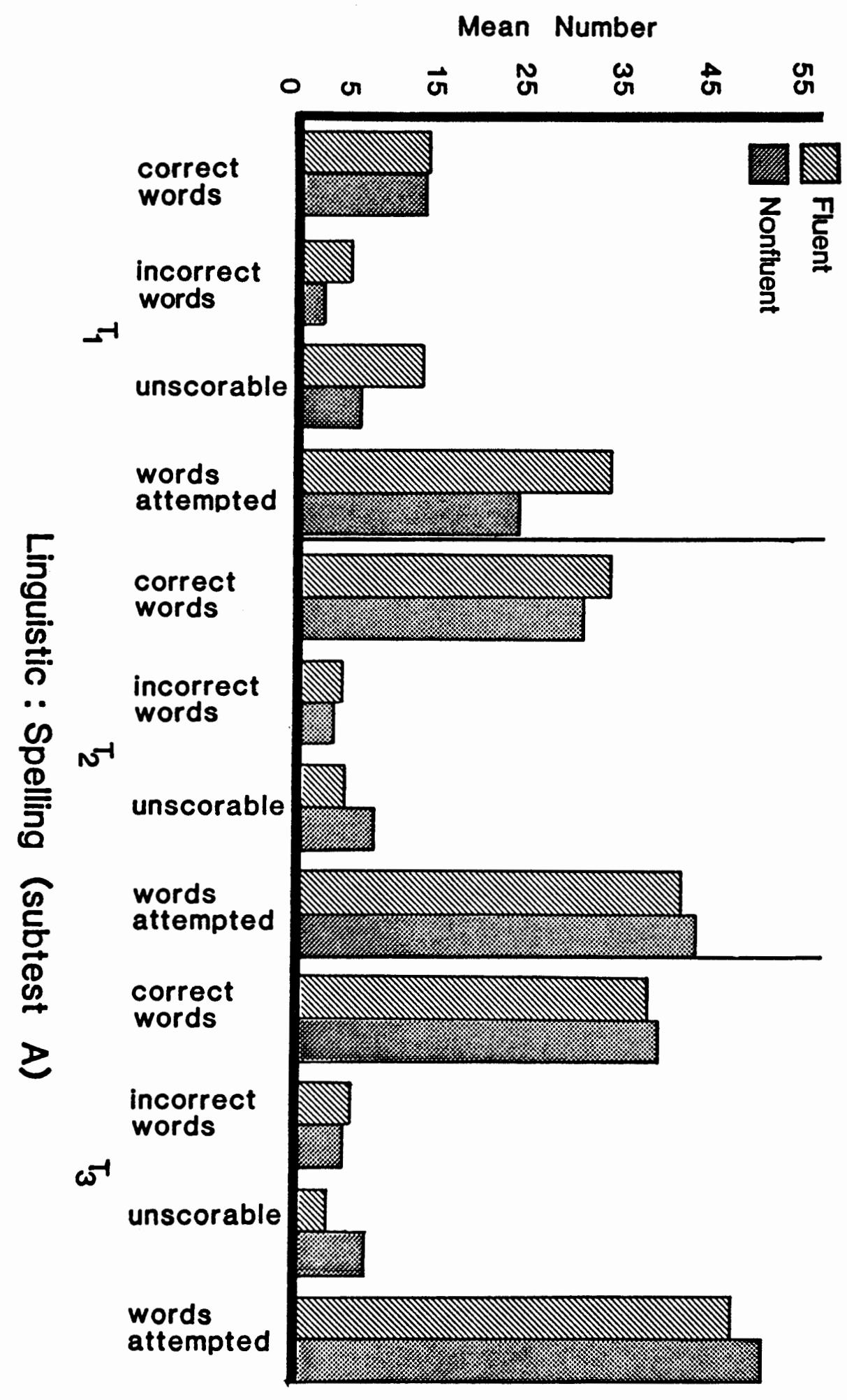

Figure 7. Linguistic spelling of fluent and nonfluent aphasic groups, Subtest A, Times I-III. 
TABLE $X$

RANK ORDER AND TOTAL WORDS

TIne I TIme II TIme III

Fluent Nonfluent Fluent Nonfluent Fluent Nonfluent

$\begin{array}{llllll}\text { Verbs } & \text { Nouns } & \text { Nouns } & \text { Nouns } & \text { Nouns } & \text { Nouns } \\ \text { Nouns } & \text { Pronouns } & \text { Verbs } & \text { Verbs } & \text { Verbs } & \text { Verbs } \\ \text { Prep. } & \text { Verbs } & \text { Prep. } & \text { Pronouns } & \text { Prep } & \text { Pronoun } \\ \text { Articles } & \text { Prep. } & \text { Artlcles } & \text { Prep. } & \text { Artlcle Article } \\ \text { Adjectlve Adjectlve Pronouns Artlcles } & \text { Pronouns Prep. } \\ \text { Pronouns Artlcles Adjectlve Adjectlve Adjectlve Adjectlve } \\ \text { Conj. }\end{array}$

TOTAL WORDS

16.2

18.5

TOTAL HORDS

37.1

37.7

46.3

TOTAL WORDS

42.9 
over nine months. Thls patlent used verbs most frequently, followed by nouns, pronouns, prepositions, adverbs, adjectlves, artlcles and conjunctions.

The nonfluent aphasic group responded differently to Subtest $A$, at $T$ ime $I$ when their most frequently used word cholce was nouns, followed by pronouns, verbs, and prepostions, whlle articles, confunctions, adjectives and adverbs were infrequently used (Table X). A similar outcome reported by Goodglass and Hunter (1970) compared the writing of a 73 year old Wernicke's aphasic patient ( 24 months post onset) with that of a 50 year old Broca's aphaslc patlent ( 3 months post onset). The authors stated that written production of the Wernicke's aphasic patient contained 25 percent verbs, and 11.8 percent nouns; the Broca's aphasic patient produced 15 percent verbs and 21.7 percent nouns.

It can be seen in Table $X$ that by Time II and again at Time III, the two groups were very simllar in their word type rank order, although the fluent aphaslc group consistently used prepositions proportionately more than the nonfluent group, and the nonfluent group used pronouns more often.

Another method of comparing the groups is to consider total graphlc output in Subtest A (Table X). At TIme I, the fluent group produced a mean score of 16.2 recognizable words in 10 sentences to describe the use of 10 items and the nonfluent group used a mean of 18.5 recognlzable words 
to accomplish the same task, with a mean difference between the groups of 2.3 words. By $T$ ime II the fluent group attempted a mean 37.7 recognizable words (a mean increase of 21 words) and the nonfluent aphasic group was almost identical with a mean score of 37.1 recognizable words (a mean increase of 1.8 words). By Time III the fluent aphasic group mean was 46.3 meaningful words compared to mean 42.9 meaningful words for the nonfluent group. Thus, the groups were similar in their use of recognizable words at each of the three time intervals. This finding is not In accordance with results descrlbed in one of the few studies found in the literature comparing graphlc production of fluent and nonfluent aphasic individuals. Goodglass and Hunter (1970) describe the written narrative of a Broca's asphasic patlent and a Wernlcke's aphaslc patient. The fluent patient wrote 144 total words compared to 97 total words in the same task by the nonfluent patient. This large difference in total graphlc production might be explalned, however, by disparate perlods of time since onset of thelr conditions. The fluent patlent was 24 months post onset, whlle the nonfluent patient was only 3 months post. It is difficult to know if syndrome differences or recovery effects were being reported.

The first variable that reached statistical slgnlflcance was unclasslfiable words types in Time I. "Unclassifiable" errors were attempts of more than two letters and looked like words but had no meaning. 
Meanlngless written word forms might be compared to the paraphasias and neologisms observed by aphasiologists when descrlbing the speech of a fluent aphasic indlvidual (Brookshire, 1978; Davis, 1983). Conversely, "unclassifiable" might be false starts resulting from motoric deficits. The fluent group produced 11.90 unclassiflable words, whlle the nonfluent group utllized fust 2.70. The fluent aphasic group produced a mean total of 28.1 word attempts in response to the stimulus, but 42 percent of thelr graphic output was "unclasslflable" and these multiple written paraphasias may have interfered with and probably reduced the efflclency of the fluent groups' written communication. The nonfluent group produced a total of 21.2 mean word attempts to subtest $A$ with only a 12 percent rate of unclasslflable words, thus they appeared more efficient in their written attempts. No data were found in the literature describing these graphically meaningless word forms and/or false starts observed in both the fluent and nonfluent groups.

Figures 4-6 demonstrate fluent and nonfluent group changes in another way, and compare their scores to those of the normal reference group. The number of graphic responses in each word type increased over time for the aphaslc groups and the ir scores became slmllar. Scores of the two groups increasingly mirrored those of the normal reference group from one to six months post onset.

Spelling. Intergroup differences were nonsignificant 
in number of correctly spelled words at each of the three time intervals (Figure 7). The groups were dissimilar, however, in number of incorrectly spelled and unscorable words at $T$ ime $I$. At Time $I$, the fluent group misspelled 25 percent of the total words, compared to 15 percent for the nonfluent aphasic group. Both groups misspelled 10 percent of written words at Time II. At TIme III, the fluent group misspelling was 12 percent, and the nonfluent error rate was 11 percent of recognizeable words. These 10-25 percent rates of misspelled words were considerably higher than those described by Ulatowska, Baker, and Stern (1979) when they reported on a group of 58 aphasic individuals ranging in severity from $m i l d$ to moderate. The group reportedly produced a spelling error rate of 1 percent when asked to write a narrative describing a picture. These authors also reported a spelling error rate of 2 percent for a Wernicke's aphasia patient observed over a nine month perlod.

At Time I, the two groups were dissimilar in the variable "unscorable" (mean 14.2 for the fluent group, and 6.3 for the nonfluent). Drawings that represented the stimulus word were included in this category cone patient consistently drew a toothbrush when asked to write the name). By TIme II and again at Time III, the fluent group production of unscorable word attempts decreased substantlally, whlle the nonfluent group slightly increased unscorable. 
Overall, the two groups' spelling was least allke at Time I. These types of differences are assumed to be the overall graphlc characteristlcs of the major syndromes of aphasia, yet in this study these characteristics occurred only at Time $I$ and the two groups were spelling in a very similar fashion in Time II and III.

Although variable responses were not generally statistically significant in Subtest $A$ at $T$ ime $I$, the two groups qualitatively followed the predicted pattern with written output mirroring probable verbal output in accordance with classification by syndrome type as described in the literature by clinlcians (Brookshire, 1978; Goodglass and Kaplan, 1972a; Margol in and Binder, 1984). At the first evaluation time, the fluent aphasic group was graphically more prolific, but thelr writing included a disproportionate percentage of unclassifiable words ( 42 percent). The nonfluent group demonstrated a lower overall number of written attempts, but the rate of unclassifiable words at 12 percent was considerably less than the fluent. The groups were also dissimilar in their rank order of word cholces when the fluent aphaslc group most often utillzed verbs, nouns and prepositions, whlle the nonfluent group used nouns, pronouns and verbs most frequently. By Time II and agaln at Time III the two groups were largely indistingulshable on all parameters and although they demonstrated a lower mean number of words than the normal reference group, their pattern of word 
types generally mirrored the normal group.

\section{Linquistic Variables for subtest B-E}

Spelling. The mean number of words spelled correctly, and number of letters added, deleted, and transposed were all very similar for the two aphasic groups $(.55$ or less difference) at each evaluation time (Figure 8). At Time I the fluent aphasic group substituted letters more frequently than the nonfluent group reaching signlflcance at $p=.043$. Although there was a significant difference between the two groups, both groups most common spelling error was letter substitution. By Time II and agaln at Time III, the two groups were largely indistinguishable in letter substitution errors.

At Time I the two groups correctly spelled about half the words right; by Time II, 70 percent were correct; and by TIme III, about 80 percent were correct. As correct spelling Increased, categorles of letters added, deleted, substituted, and transposed generally decreased.

At each evaluation time the similarities in approach to spelling are more striking than the differences, and evaluation of incorrect responses provided little insight Into spelling strategies. This observation is in accordance with Wapner and Gardner's (1979) study of 31 fluent and nonfluent aphaslc individuals. The authors noted that spelling ability tends to reflect other linguistic abllities and that the slmllarlty of error profiles 


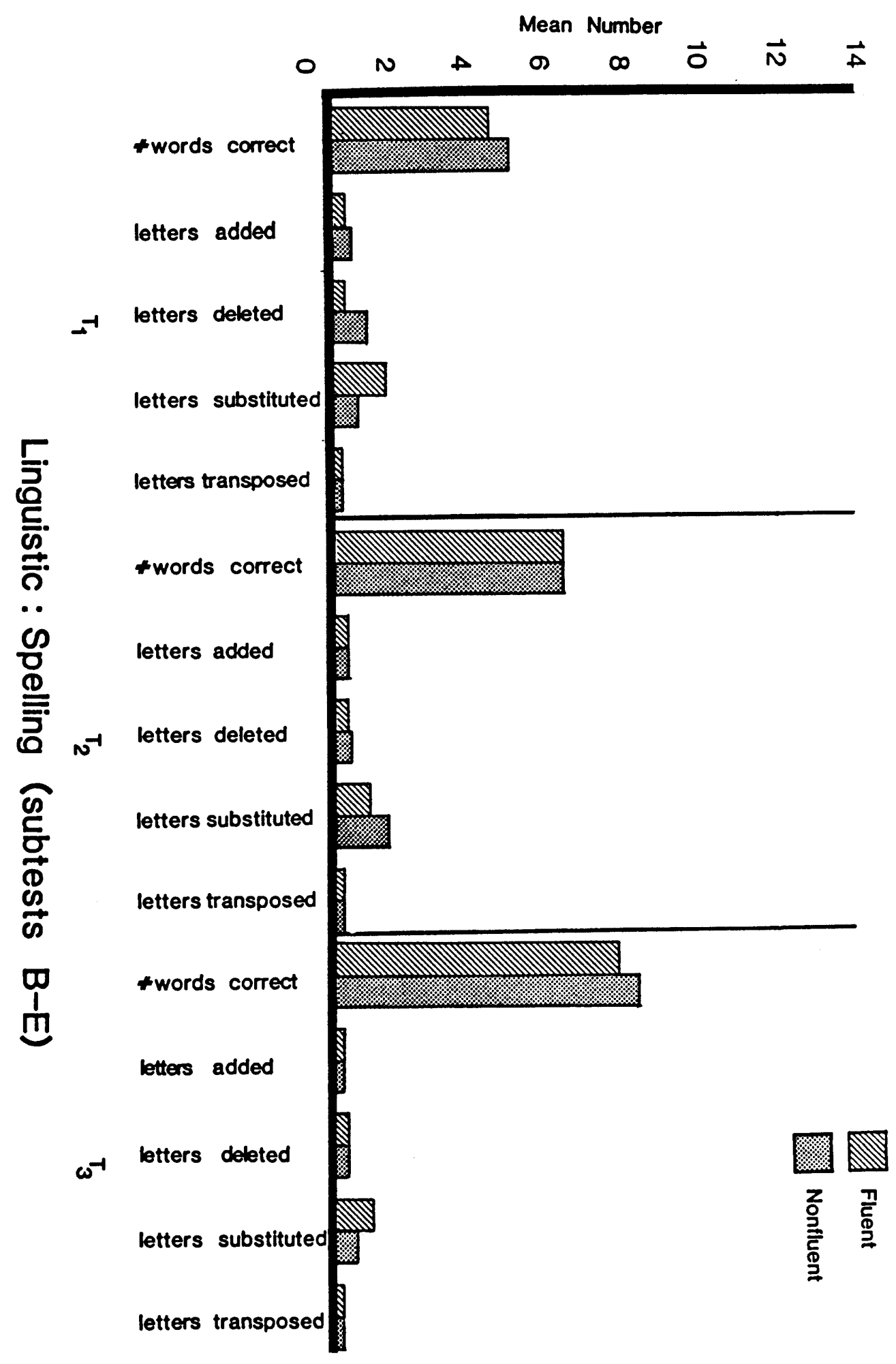

Figure 8. Linguistic spelling of fluent and nonfluent aphasic groups, Subtests B-E, Times I-III. 
indicate an approach to spelling common to all patients.

Word Error Type. The fluent and nonfluent aphasic groups produced approximately the same number of recognizeable words in Time I and II (Figure 9); however, at Time III the nonfluent group increased to a mean of 1.5 more recognizeable words than the fluent group. In Time I, the fluent group produced more neologlsms (4.62) than the nonfluent group (2.69) and this variable approached significance. This outcome was predicted by aphaslologists (Marcie and Hecaen, 1979; Margol in and Blnder, 1984). Other variable responses, (semantically related, paraphsias, and perseverations) at each time period were Indistinguishable. This similarity was unexpected according to views commonly stated in aphasia literature (Brookshire, 1978; Marcle and Hecaen, 1979; Margol In and Binder, 1984).

The two groups appeared similar in word error types and rate of recovery, al though the fluent aphasic group made slightly more neologistic errors than the nonfluent group. The results indicated common graphlc word production strategies.

\section{Motor Variables}

Letter Execution. At each time, the most common letter production error for both groups was "ambiguous letters"; however, the difference between the two groups at Time I was negligible (Figure 10). At Time II and Time 


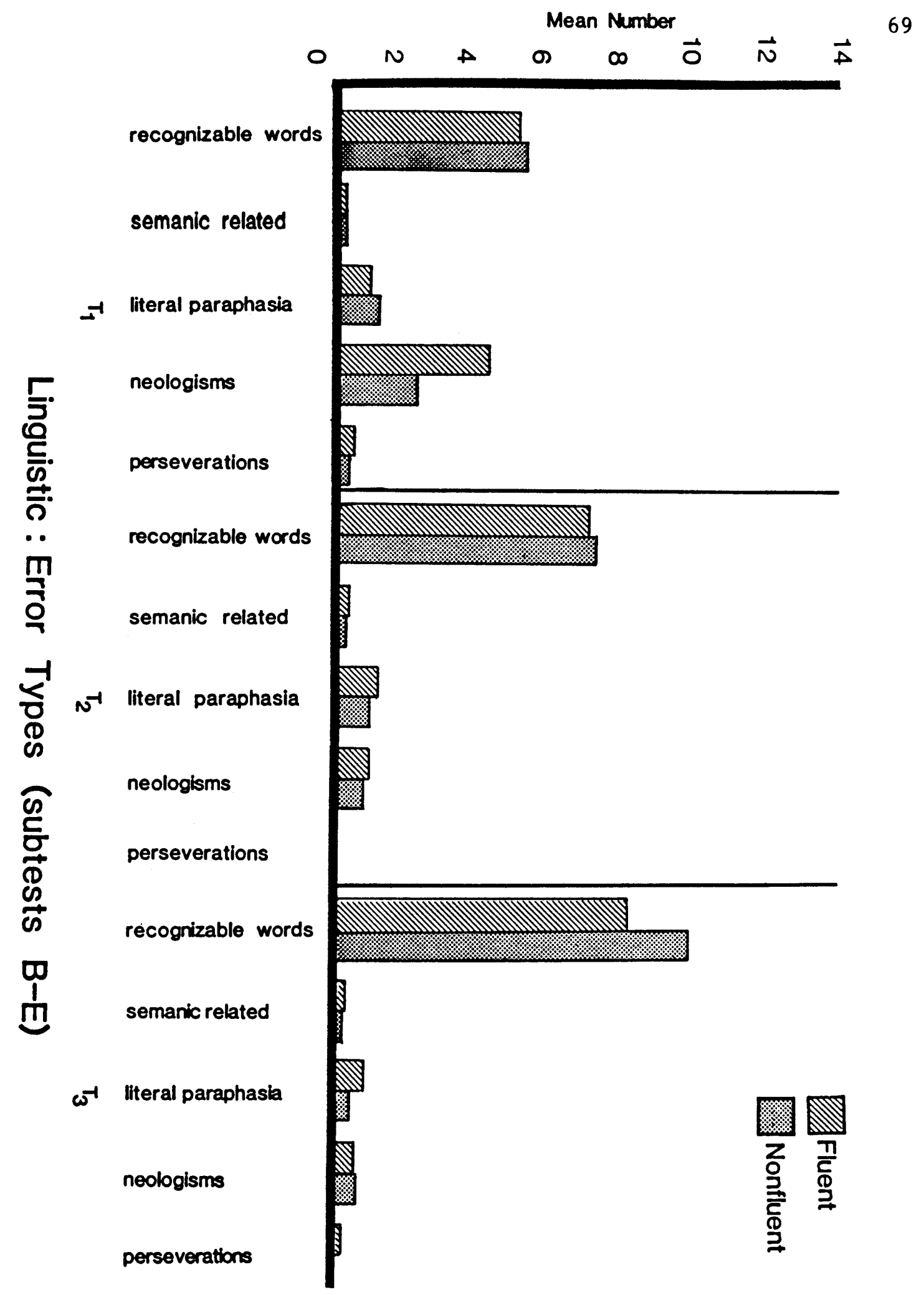

Figure 9. Linguistic word error types of fluent and nonfluent aphasic groups in Subtests B-E, Times I-III. 


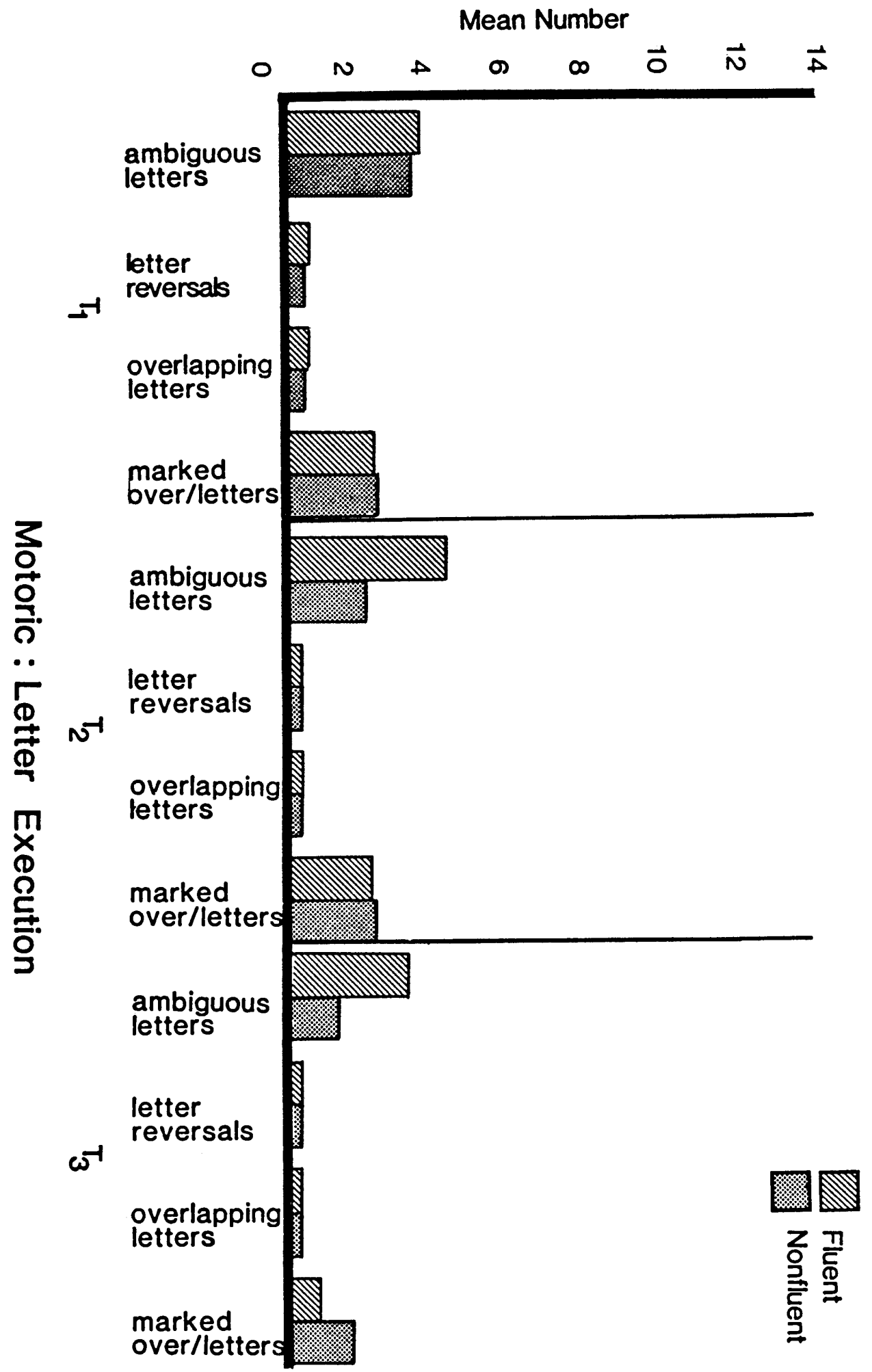

Figure 10. Motoric letter execution errors of fluent and nonfluent aphasic groups, Subtests A-E, Times I-III. 
III, the differences between the two aphasic groups' ambiguous letters increased to a mean of 1.93 and approached significance when the fluent group produced more ambiguous letters. There was little intergroup difference of letter reversals and overlapping letters at any of the time periods.

At Time II, the fluent aphasic group decreased their already minimal use of overmarking letters while the nonfluent group remained almost constant across the three time periods. By Time III, a mean difference of 1 was evident between the two groups and overmarking approached a level of significance with the nonfluent group producing this error more frequently.

The two groups looked most alike at Time $I$ and least alike at $T$ ime II when the fluent group wrote slightly more ambiguous letters, and the nonfluent group marked over letters more often. Letter reversals and overlapping letters had almost disappeared by Time III for both groups, but both groups continued to make ambiguous letter and mark over errors.

Letter size, At each of the three time intervals graphic output of both groups was generally within $1 \mathrm{~cm}$ in size. In Time I there was a negligible difference between the two groups. At Time II there was a 7 percent difference. A 14 percent difference was found at Time III. The fluent aphasic group appeared more diverse in letter size selection since almost 10 percent chose to write 
smaller than $1 / 2 \mathrm{~cm}$, and 10 percent wrote larger than $1 \mathrm{~cm}$. The nonfluent aphasic group wrote $1 / 2-1 \mathrm{~cm}$ in size in 94 percent of the samples (Flgure 11). No Information describing letter size in relation to syndrome of aphasia or recovery was found in the literature for comparison to these findings.

Line Execution. At Time I there is a 13 percent difference in mean scores between fluent and nonfluent aphasic group scores on the variable "tremor" (wavy, shaky) lines, with the nonfluent group producing more of this error type. At the same evaluation time, the nonfluent group produced 16 percent more nonfluld lines than the fluent group. "Nonfluid" lines indicated that the line was not smooth flowing in appearance and/or contalned some apparent motor difficulties. The differences between the two groups on the variable "nonhorizontal lines" was negligible.

Tremor reduced for both groups at $T I m e$ II, and the two groups looked alike. Both groups somewhat diminished the number of nonfluid items, although the difference between their mean scores was almost 14 percent, with the nonfluent group producing more nonfluid lines. During this same time, the graphic output of both groups became more horlzontal.

By Time III, the fluent group reduced tremulous lines to a minimum, but the nonfluent group mean percent remained at almost 6 percent. Each group was writing in a more 


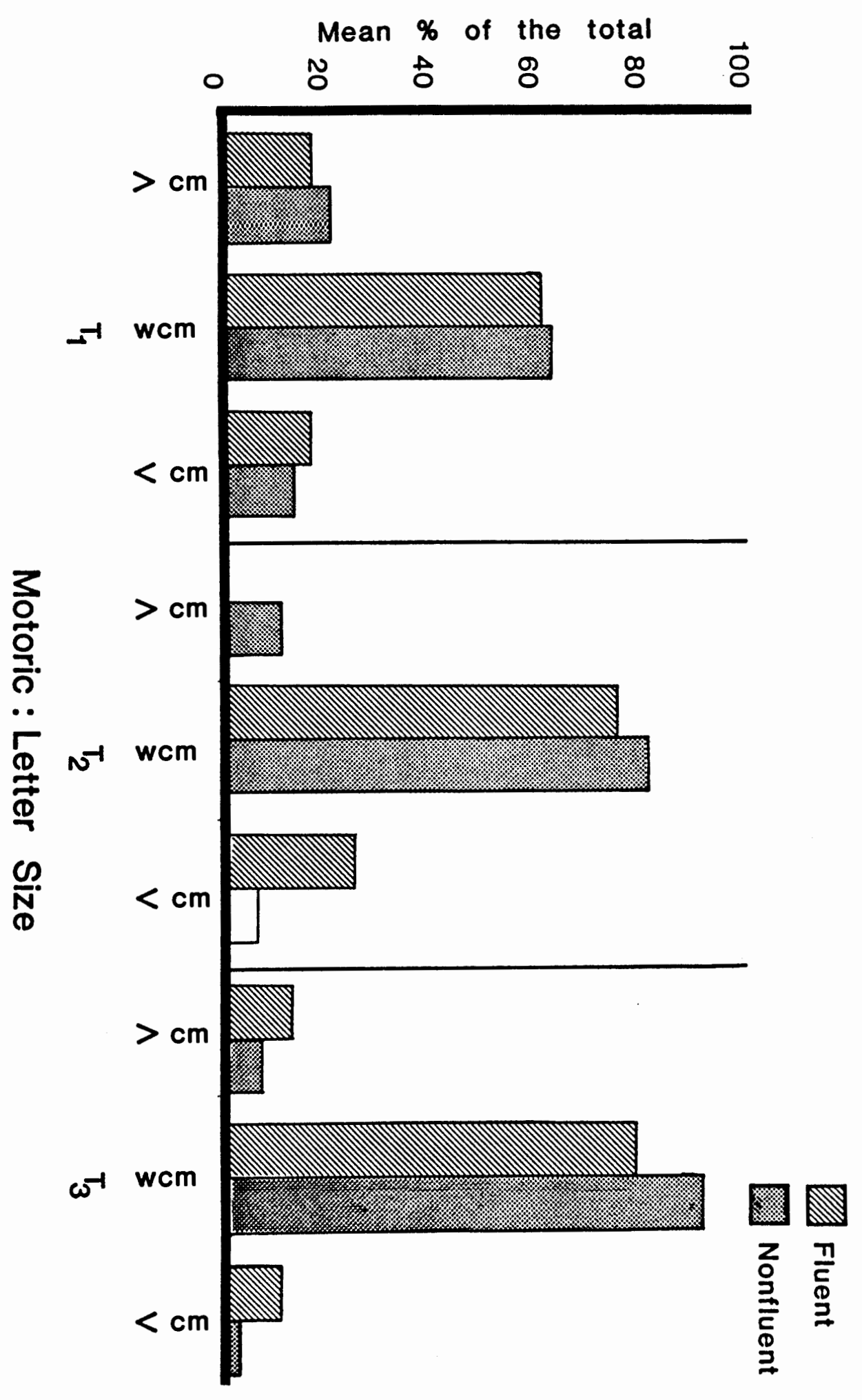

Figure 11. Motoric letter size produced by fluent and nonfluent aphasic groups, Subtests A-E, Times I-III. 
fluid manner and the difference between them had reduced to 8.55 percent, with the nonfluent group making more of this type of error. At this time period, "nonhorizontal" increased slightly for both groups to about 10 percent (Figure 12).

In summary, "nonfluid" was the most prevelant line execution error for both groups, with the nonfluent group producing slightly more of these errors. These errors slowly diminished over time, but stlll occurred In 29 percent and 38 percent respectively of the fluent and nonfluent groups written production at final evaluation. Other line execution errors (tremor and nonhorlzontal) diminlshed over time and differences between the groups remained slight.

Motoric letter style. At Time I, both groups preferred "manuscript" writing (printing) and each group mean score was slightly more than 60 percent. At this time, the two groups were similar in production of curslve handwriting, with a mean of about 38 percent. The nonfluent aphaslc group did not utllize "mlxed" handwrlting, whlle the fluent group produced a mean score of 1.6 percent (Figure 13). By Time II, the use of manuscrlpt writing had diminlshed for both groups, with the fluent group producing a little more. Cursive writing increased at $T$ ime II, with the nonfluent utilizing this style a little more. Mixed writing style was seldom used and became negliglble by Time II. By Time III a little 


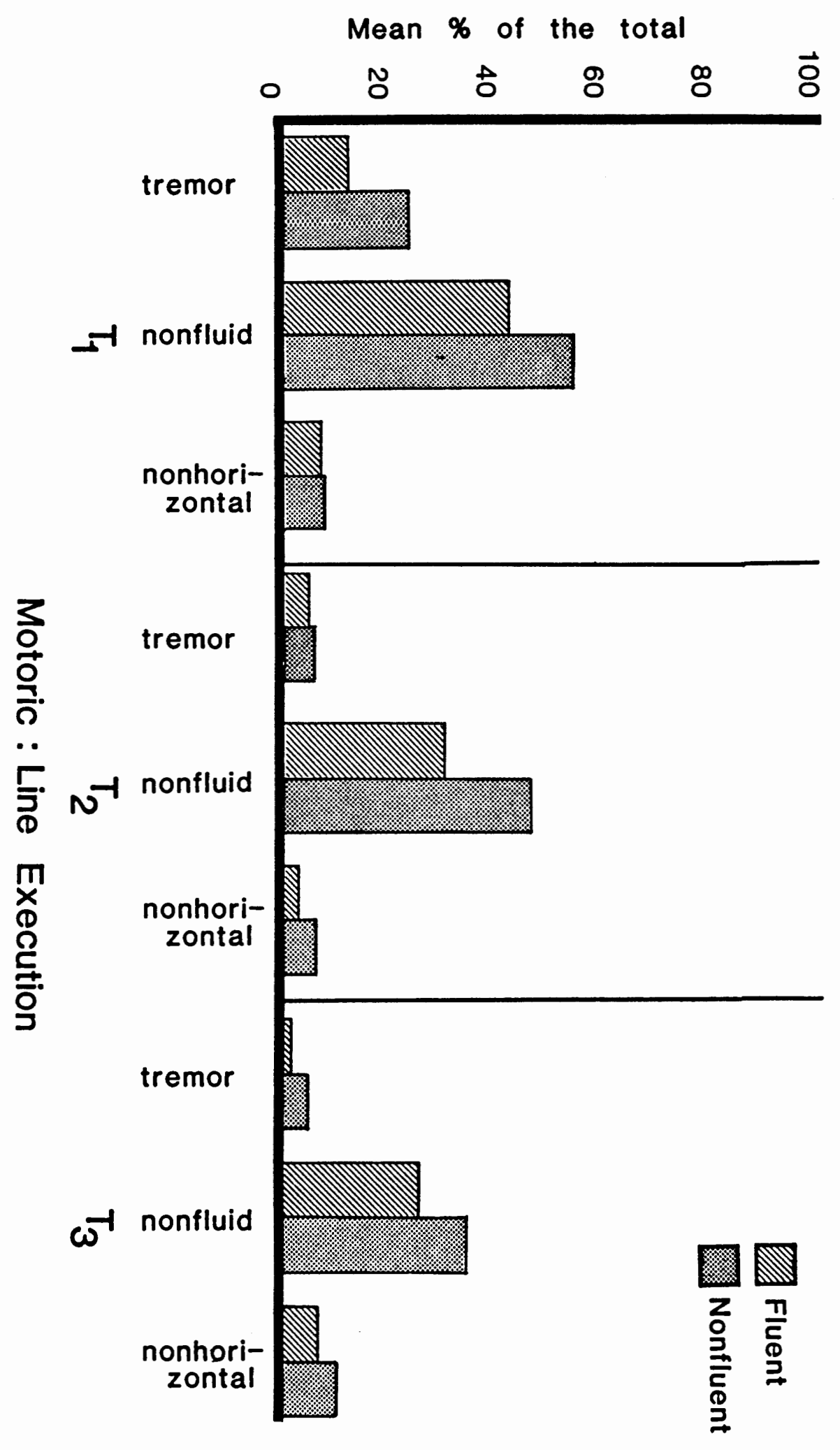

Figure 12. Motoric line execution errors produced by fluent and nonfluent aphasic groups at Times I-III, Subtests A-E. 


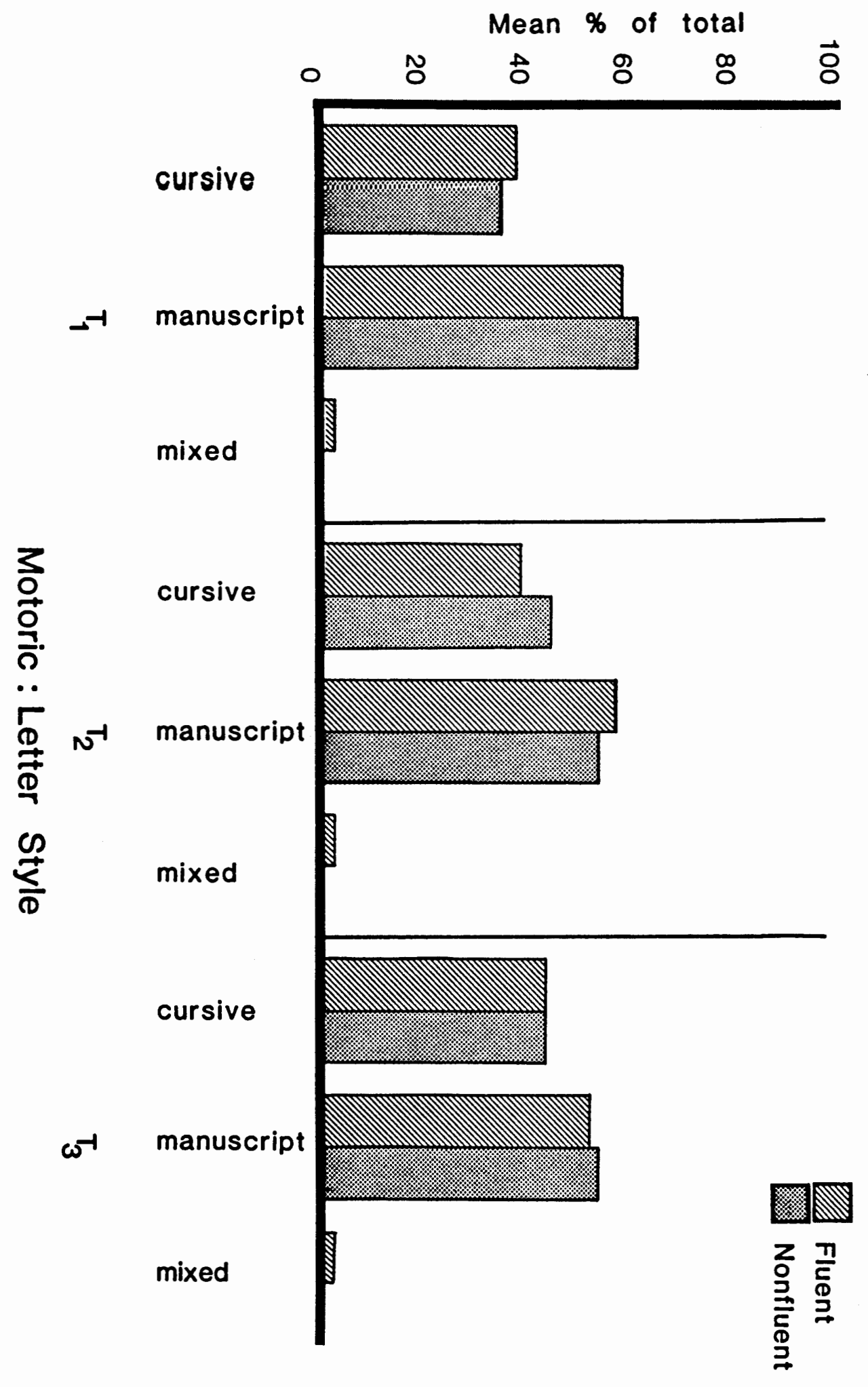

Figure 13. Motoric letter styles produced by fluent and nonfluent aphasic groups at Times I-III, Subtests A-E. 
more than half of both groups preferred manuscrlpt wrlting, and a little less than half of both groups preferred cursive writing.

After studying 30 aphaslc Individuals with varying etiologies and varying months past onset, Boone and Friedman (1976) concluded there was no advantage of one writing form (cursive or manuscript) over another. They did note however, that some patients were considerably more successful with one or another form. Thls study did not find any writing preference according to syndrome.

\section{Inter-Group Comparison Summary}

Performance differences between the two groups for almost all motoric and $l$ inguistic features were minor, and statistlcal slgniflcance was reached on only two varlables. These variables which occurred at Tlme I were "unclassifiable" in Subtest $A$, and "letter substitution" in spelling, Subtests $B-E$.

Linguistic nonstatistical differences were notable only at $T$ ime I, and by $T$ imes II and III the two groups were indistinguishable. Conversely, motorlc intergroup differences did appear over time. These differences included a larger number of ambiguous letters produced by the fluent group, and larger number of marked over letters and nonfluid errors produced by the nonfluent group. Both groups Increased "nonhorlzontal wrlting" by Time III. 
Linguistic errors decreased substantlally with time, but motoric errors improved much more slowly, and one varlable ("nonhorlzontal") even Increased with time. The premise that fluent and nonfluent aphasic written production would mirror oral production as defined by syndrome type may be true for only a few variable and only in Time I. The literature makes assumptions after comparing aphasic patients with varying etiologies, handedness, ages, and tlme post onset. Generallzations are made on the basis of single subject reports or small group comparisons. Frequently generalizations are made after studying only mild or only severely impaired aphaslc patients (Keenan, 1971; Mohr, Sidman, Stoddard, Leicester, and Rosenberger, 1973; Ulatowska, Hildebrand, and Haynes, 1978).

This study, which controlled for age, handedness, sex, etiology, severity and time post onset, suggests that syndrome type is less important than time post onset. This study suggests that qualitatively some minor differences may exsist in the first few months (1-3) post onset, but these differences largely disappeared after three months. Finally, findings suggest motoric recovery lags behind linguistic recovery. This observation has not been made in previous research.

\section{Between-Time Interval Differences}

The second major conslderation of thls paper was an 
evaluation of graphlc changes durling recovery of the combined fluent and nonfluent aphasic groups.

\section{Linaulstle Varlables for subtest A}

Word Types. Five of seven word types reached level of signficance (p.<.05) during at least one of the evaluation times (Tables IV-VII). Parameters reaching significance between Time I and Time II included verbs, prepositions, articles and nouns. Pronouns reached level of significance between Times II and III. Flgure 14 11 lustrates changes that occurred over the three evaluation times. It can be seen that generally the frequency of different word types increased substantially, with nouns and verbs being the most frequently used parts of speech at all time intervals. Unclassifiable words decreased over time. These results are similar to those reported by Elvin and Oldfleld (1951) when they assessed the graphlc production of an aphasic university student. The student produced a comparatively high number of verbs and nouns and a relatively low number of articles, prepostions and pronouns.

Figures 15-17 compare combined fluent and nonfluent group graphlc responses with the normal reference group at 1,3, and 6 months post onset. Although the combined group cholces generally mirror those of the normal reference group, the ratio of verbs to nouns does not follow that of 


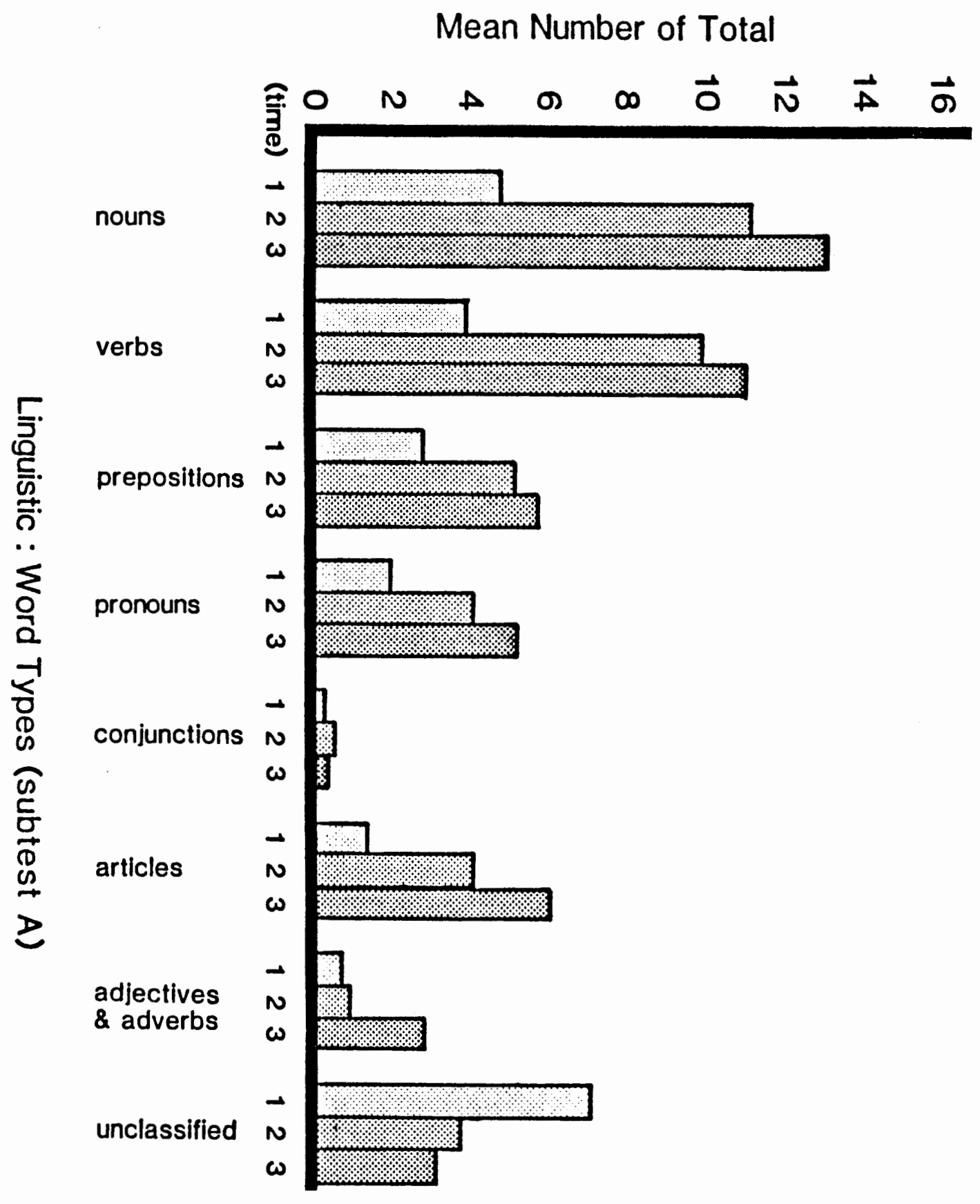

Figure 14. Linguistic word types used by the aphasic group at three intervals of recovery, Subtest A. 


\section{Mean Number}

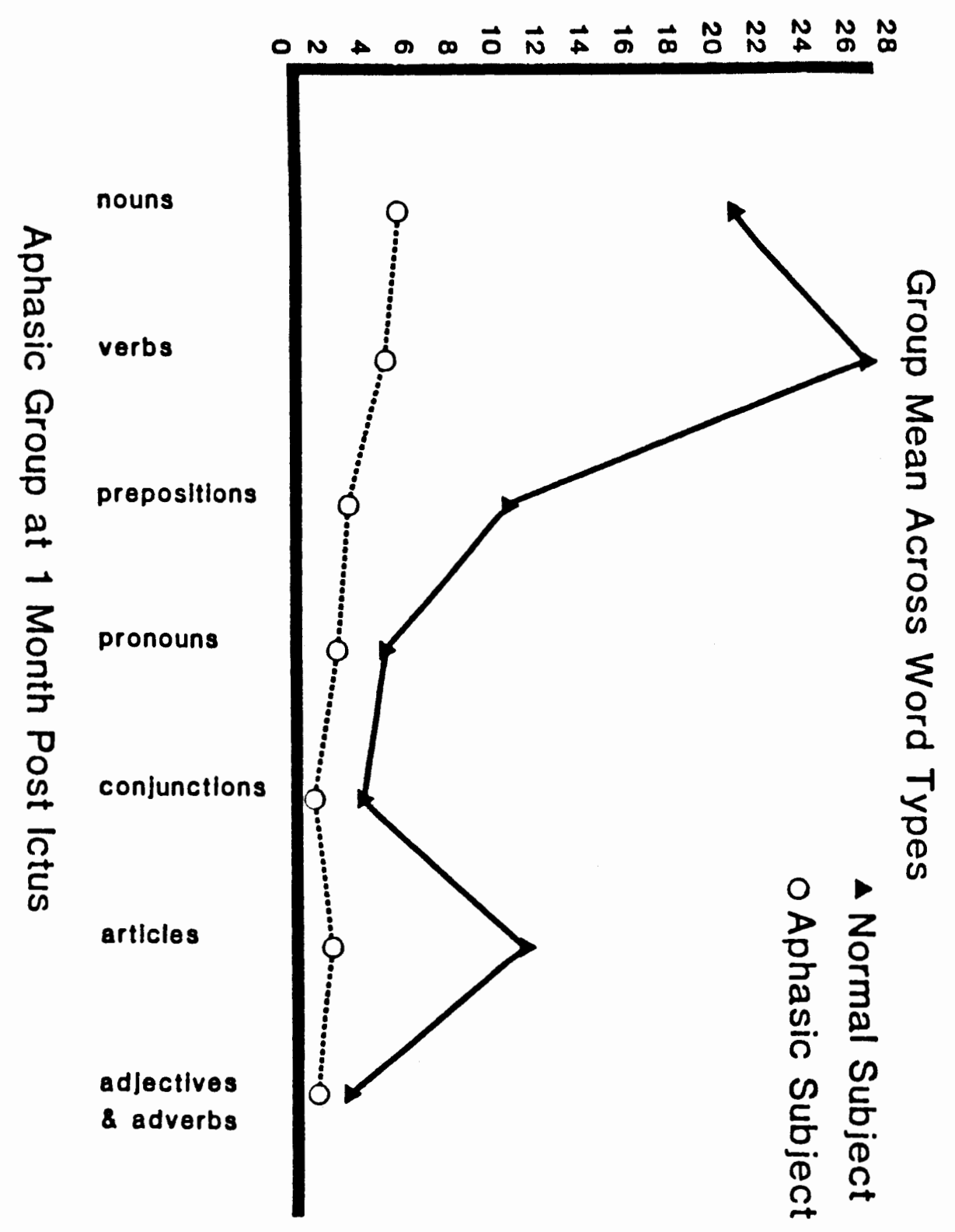

Figure 15. Linguistic comparison of word types produced by normal and aphasic subjects at Time I, Subtest A. 


\section{Mean Number}

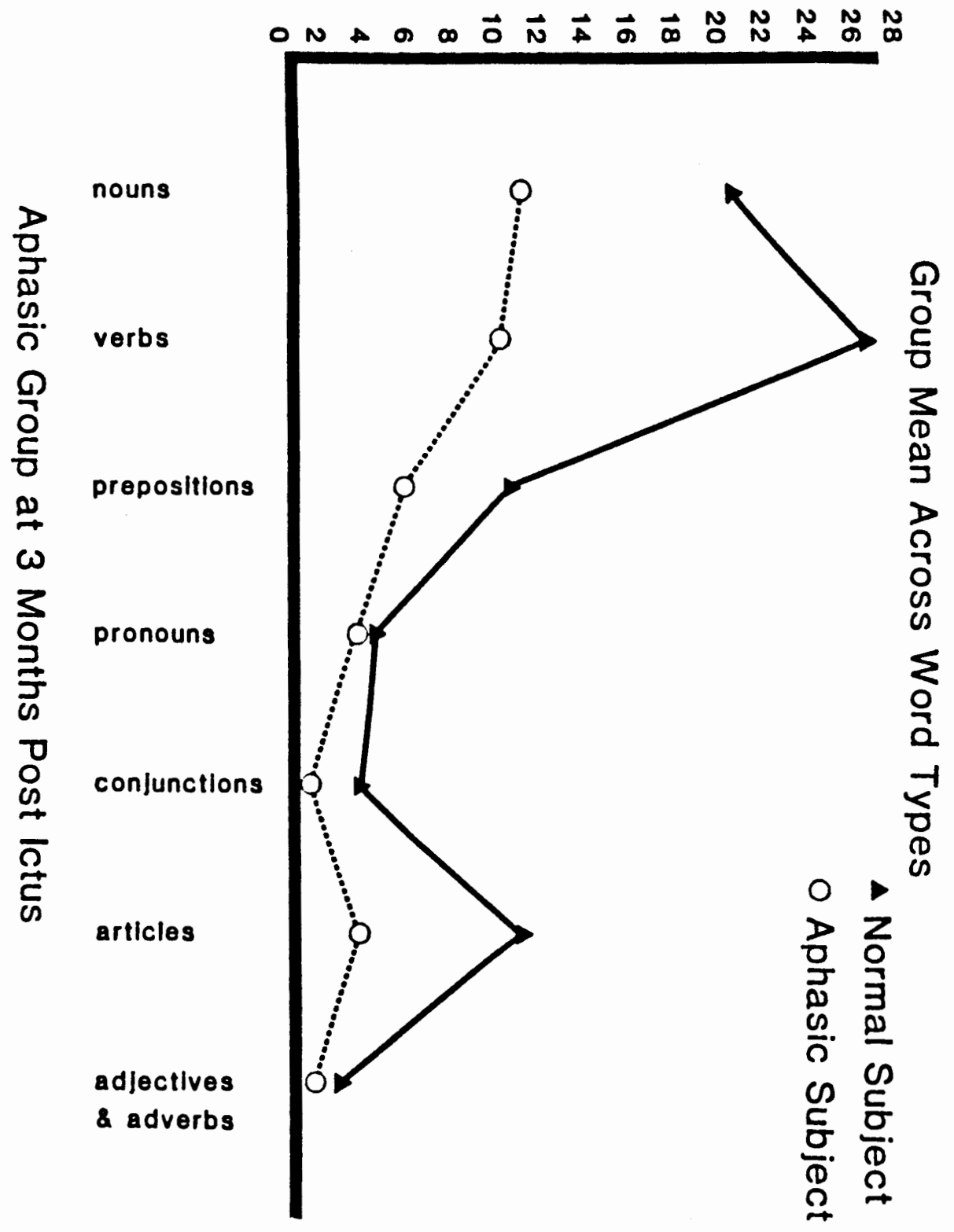

Figure 16. Linguistic comparison of word types produced by normal and aphasic subjects at Time II, Subtest A. 


\section{Mean Number}

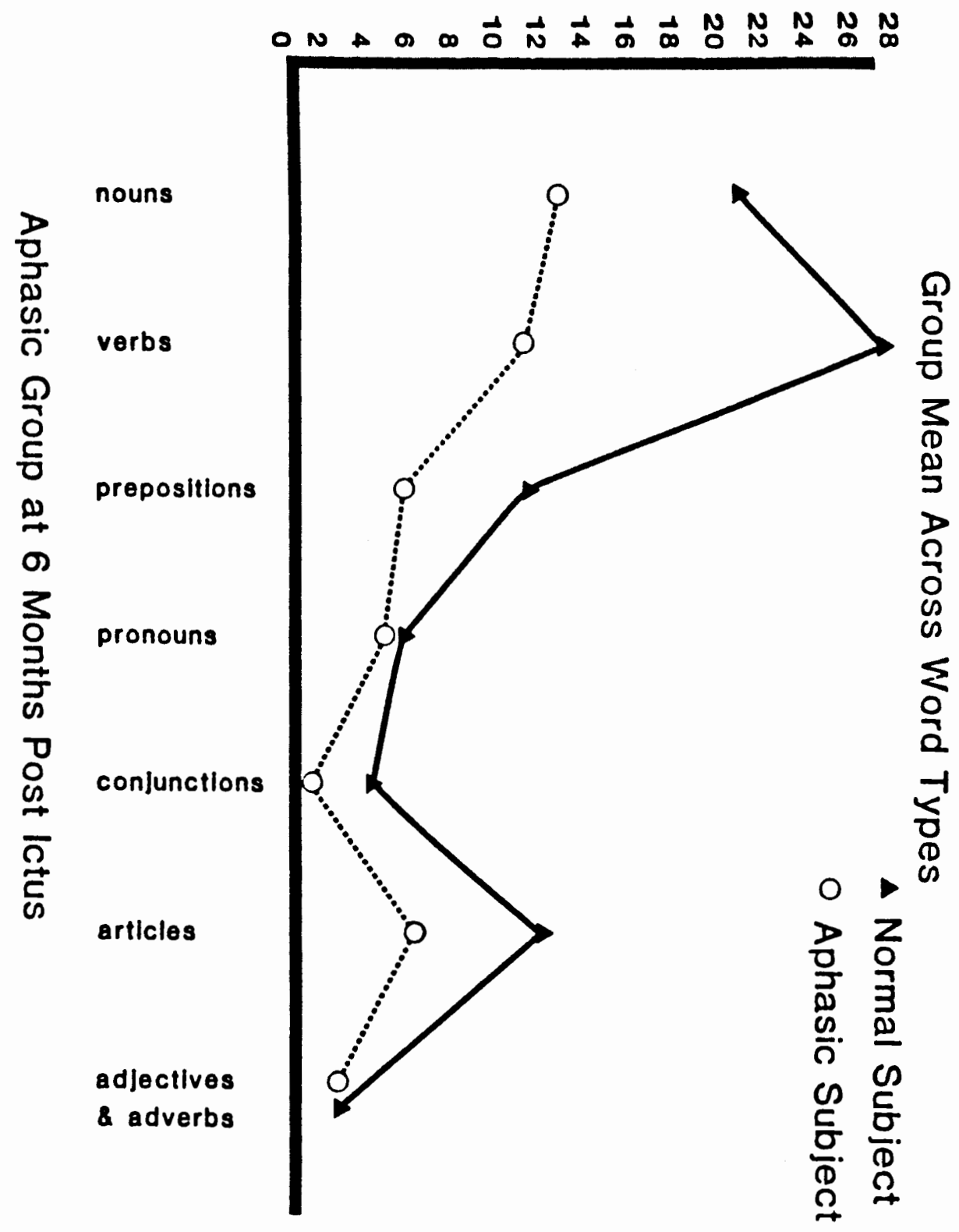

Figure 17. Linguistic comparison of word types produced by normal and aphasic subjects at Time III, Subtest A. 
the reference group. The aphasic groups used primarlly nouns in written language, while the reference group used primarlly verbs (including gerunds and infinltives).

Seelling. Figure 18 demonstrates increases in the number of words spelled correctly at each of the evaluation times. Incorrectly spelled words increased slightly at each time in relation to greater increases in number of words correct at each of the three time intervals. Unscorable words decreased substantially over time. Differences in the number of correct words were significant at each time time interval indicating improvement over time; however, the aphasic subjects spelled 12 percent of the test words wrong at Time III.

\section{Linguistic Variables for subtest $B-E$}

Spelling. The number of words spelled correctly Increased slgniflcantly at approximately 1, 3, and 6 months post onset. Figure 19 demonstrates a moderate, consistent gain of about 1.5 words (out of a possible 10 words) at each evaluation time. At the final evaluation, the combined fluent and and nonfluent aphasic group spelled about 80 percent of subtest B-E correctly. The number of letters added, deleted, substituted and transposed were minimal at one month post onset and diminished over time as number of words spelled correctly increased.

Wapner and Gardner (1979) reported graphic single word spelling tasks of 39 aphaslc patients (severity and 


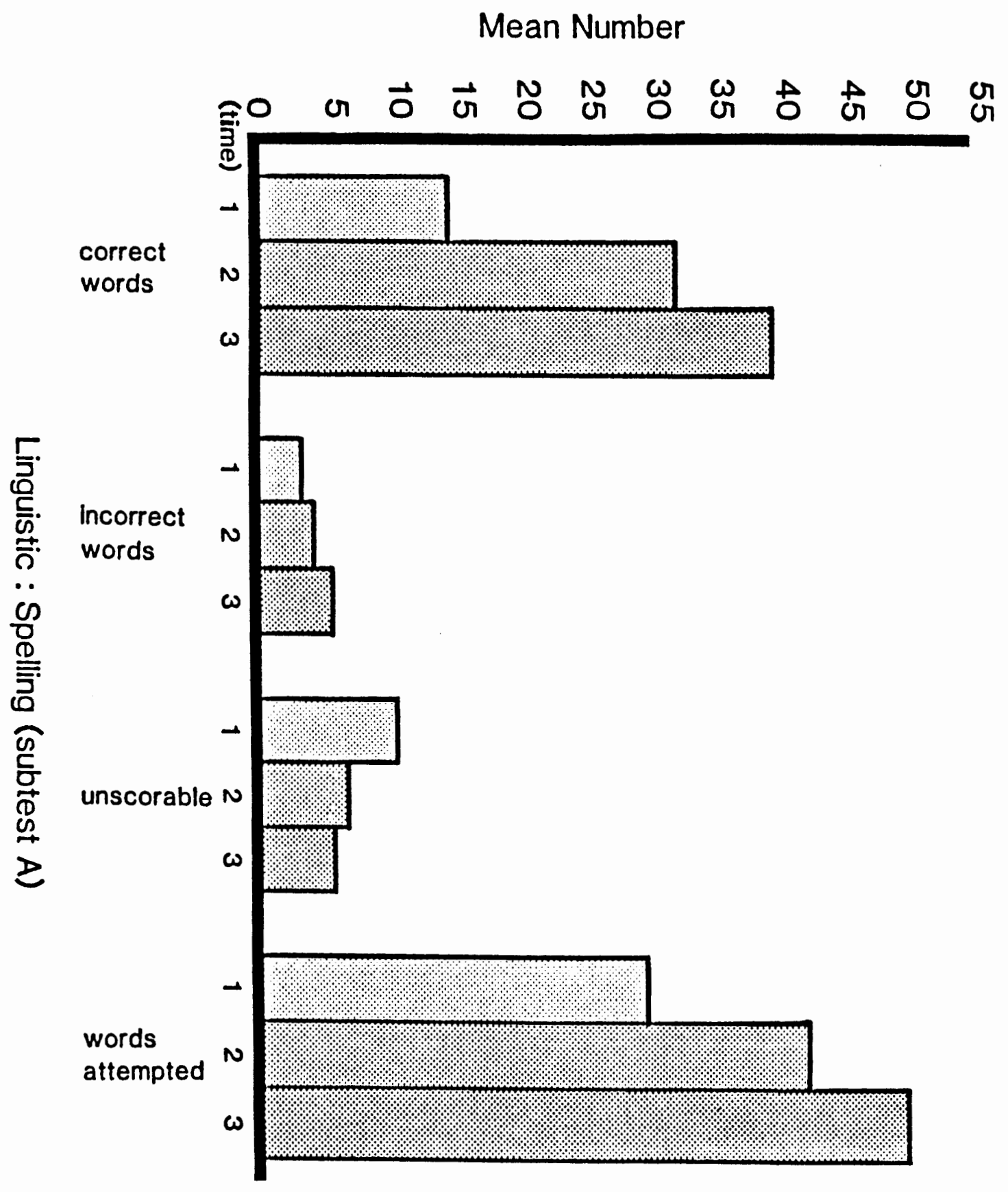

Figure 18. Linguistic spelling errors of the aphasic group at three intervals of recovery, Subtest $A$. 
months post onset were not reported). The authors found that errors of substitution were the most common spelling error, followed by errors of omission, addltion and reversals. This was the general pattern observed in this study.

Word Error Types. Four of five variables' difference scores were statlstically slgnlficant between at least one of the evaluation times. The number of recognizable words Increased slgniflcantly between each of the evaluation periods (Figure 20). By Time III, the combined groups production, on average, of Subtests $B-E$ was 85 percent recognizable. Literal paraphasias were signlficant at Time I when a substantial decrease was found. Neologisms, the most common error type, decreased significantly from Time I to $T$ ime II and Time I to Time III (mean 3.62 decreased to $.82)$.

Perseveration scores, which were minimal at Time I, reached a level of statistical slgnlficance when they decreased between Time I and II. Perseveration increased slightly between times II-III.

In summary, the aphasic group demonstrated linguistic improvment over time. All word types increased, with nouns and verbs fairly equally represented in graphic production at Time III. The noun-verb ratio for the aphasic group appeared different than that of the normal group, who used considerably more verbs than nouns when responding to 
Mean Number

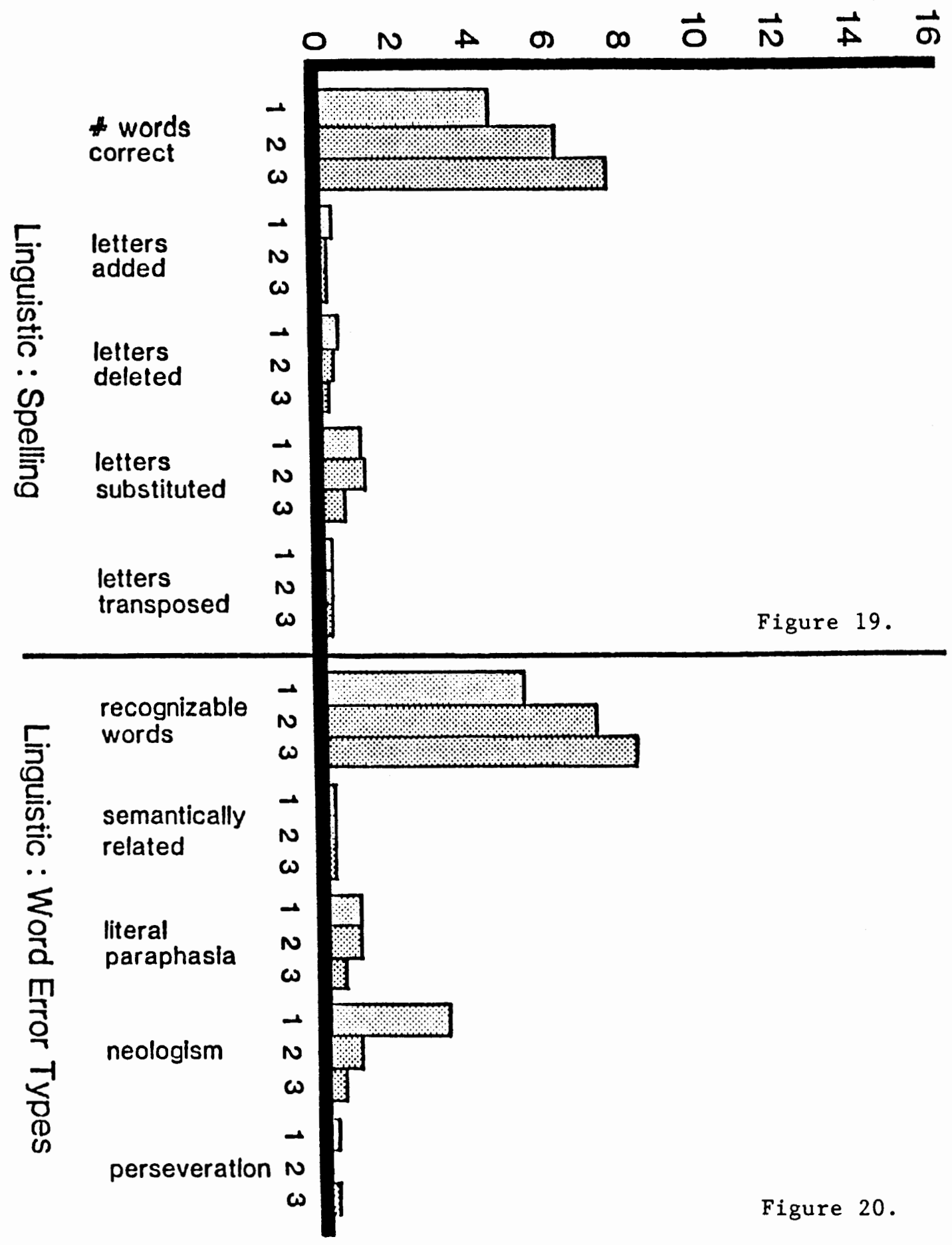

Figure 19. Linguistic spelling errors of the aphasic group, Subtests $B-E$ over three intervals of recovery.

Figure 20. Linguistic word error types of the aphasic group, Subtests $B-E$, over three intervals of recovery. 
Graphic subtest A. The number of recognizable words increased over time as error types decreased. Neologisms were the most common error type, followed by paraphaslas. Both of these error types decreased signiflcantly over time. Spelling limproved in sentences and single words, and was about 88 and 80 percent correct respectively at $T$ ime I I .

\section{Motoric Variables}

Changes in scores for only a few motoric parameters reached a statistically significant level. The following discussion describes those variables where significant changes occurred and those variables where scores failed to reach significance.

Letter Execution. No letter execution error type change scores reached a statistical significance. Although relatively few in numbers, ambiguous letters and marked over letters decreased gradually across the three samples, but remained the most prominent error type throughout. Letter reversals remained relatively consistent across time. Overlapping letters Increased slightly by TIme III, but mean scores remained low (Figure 21 ).

Letter size. Differences in scores for letter size parameters reached significance between at least one of the measurement times. Writing within $1 / 2-1 \mathrm{~cm}$ was the most common writing size at each evaluation time and reached a level of significance in the overall time measurement 


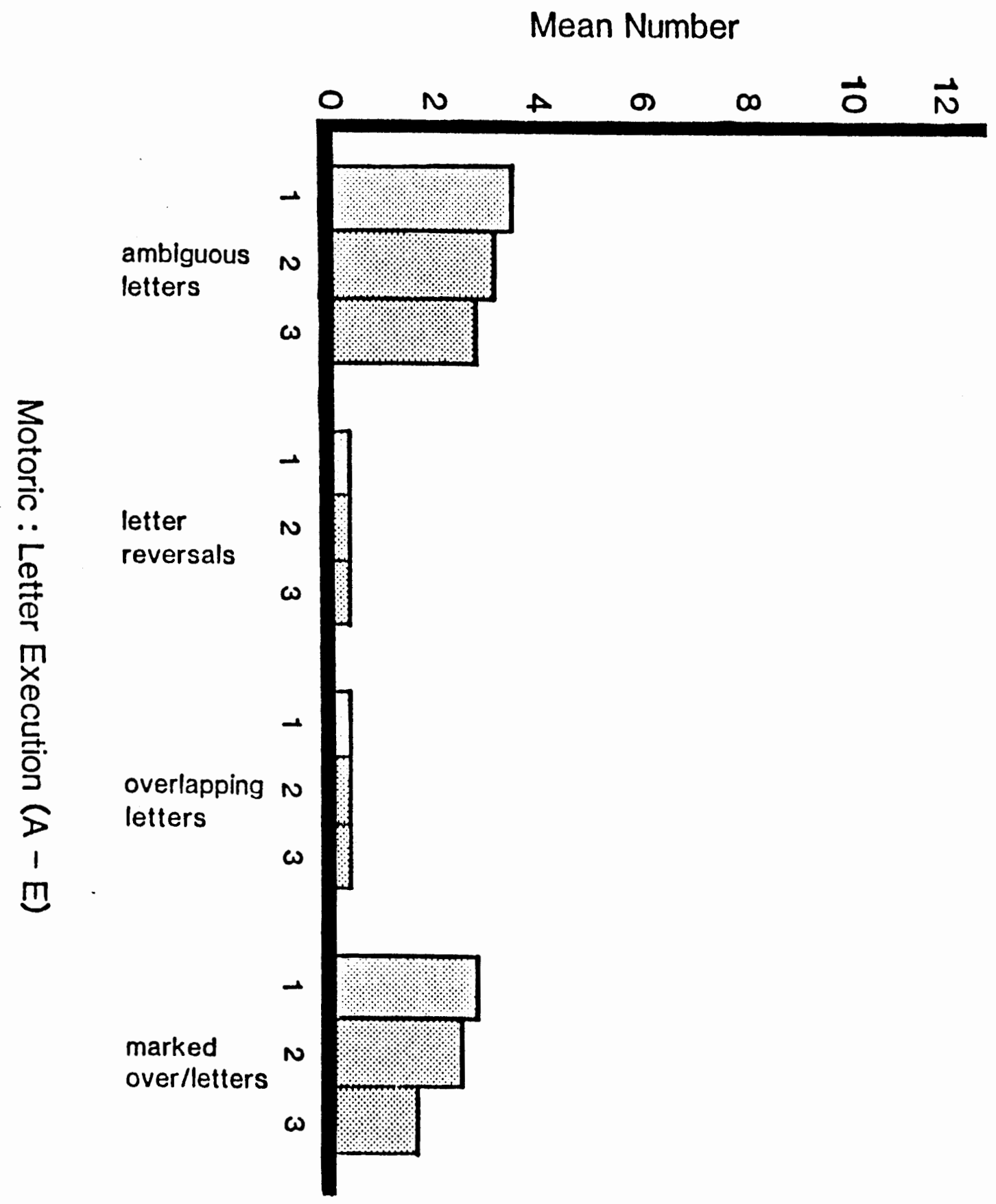

Figure 21. Motoric letter execution errors of the aphasic group, Subtest $A-E$, at three intervals of recovery. 
(TImes I-III) and approached signlflcance by TIme II. The overall percentage of written samples within $1 \mathrm{~cm}$ increased from a mean of 63 percent at Time $I$ to 87 percent at Time III. Writing larger than $1 \mathrm{~cm}$ was most prevelant at Time I (mean 19 percent), but a significant reduction occurred between Times I and II. BY Time III, the subjects' graphic production larger than $1 \mathrm{~cm}$ was was about 7 percent. Handwriting smaller than $1 / 2 \mathrm{~cm}$ occurred at Time I with a mean of 17 percent, and reached a level of significance by Time II and by Time III and ultimately about 7 percent of the combined group sample was less than $1 / 2 \mathrm{~cm}$ in size (Figure 22).

Line Execution. Tremulous handwriting was most prevelant at $T$ ime I when about 17 percent of the graphic production was thus described. Changes in scores reached a statistically significant level by $T$ ime II and again in overall measurement between Time I and III. By Time III, a mean of only 3 percent of the combined groups' graphic output was described as tremulous. The most common line execution deficit was "nonfluid" (not smooth flowing and with obvious motorlc difficulties). At Time I over 50 percent of the groups written lines were consldered to be nonfluid. Score changes in this parameter reached a level of signiflcance between times II and III, and again overall (Time I to III)(Figure 23 ).

Letter Style. (Figure 24). Changes in scores of neither manuscript nor cursive writing reached a 


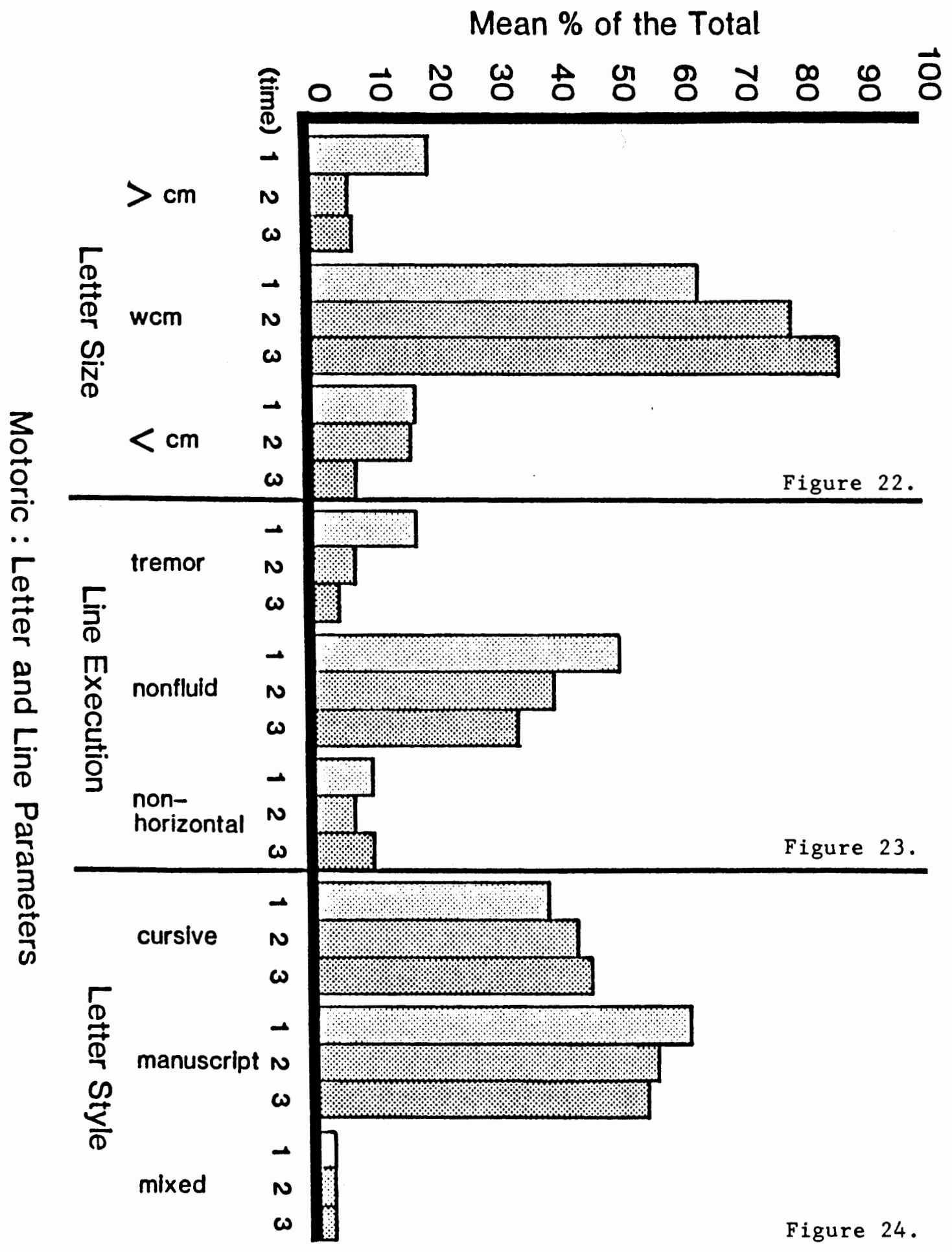

Figure 22. Motoric letter size of aphasic group over three intervals of recovery, Subtests A-E.

Figure 23. Motoric line execution characteristics of aphasic group over three intervals of recovery, Subtests A-E.

Figure 24. Motoric letter styles of aphasic group over three intervals of recovery, Subtests A-E. 
statistically significant level at any evaluation time. Most of the group of combined fluent and nonfluent aphasic Individuals chose printing at Time I (mean 61 percent), but this diminished to a mean of 54 percent by Time III. Cursive writing increased from a mean of 38 percent at $T$ ime I to mean 45 percent at Time III.

\section{Summary}

Overall, for most of the variables examined, significant changes occurred toward improvement. Linguistic improvement reached significant levels between Time I and II. Scores of ten of the twenty-two linguistic variables demonstrated significant changes between $T$ imes $I$ and II, and one more variable score demonstrated significant change between Time I and III. Scores of three of thirteen motorlc variables demonstrated significant change between Times I and II, and a total of four demonstrated change in the overall evaluation times. Consequently, about half of the linguistic variable scores and one third of the motoric variable scores demonstrated significant change over time for the combined groups. 


\section{CHAPTER V}

\section{SUMMARY AND IMPLICATIONS}

\section{SUMMARY}

The purpose of this study was to compare the graphic production of fluent and nonfluent aphasic groups in terms of motoric and $I$ inguistic characteristics at three intervals of recovery. The study also sought to analyze change at each of three evaluation periods after combining the fluent and nonfluent aphasic groups.

Evaluations were made at roughly one, three and $s$ ix months post onset. Writing samples from a total of 25 subjects included 10 fluent aphasic patients, 10 nonfluent aphasic patients and a reference group of 5 age matched nonneurologlcally impalred subjects. Samples of wrltten responses were taken in a retrospective manner from files of patients who had received speech pathology treatment at the Portland Veterans Administration Medical Center within the preceding 12 year period. All written samples included responses to the Porch Index of Communicative Ability (PICA) graphic subtests administered at one, three and six months post onset. The normal reference group was administered the PICA once and graphic subtests were Included in the sampling serles for analysis. Findings 
from the normal group were used for graphic comparisons to performances from the experimental group.

The aphaslc patlents were all male, premorbldly right handed, aged 52 to 65 years, premorbidly literate, and had all suffered thromboembolic CVAs that involved the left hemisphere of the brain. The groups had an equivalent range and mean for BICA Overall severity percentile at one month post onset.

Identifylng features were removed from subtest copies. All subtests were randomized across group and subtest sampling time. Previously determined criteria were applied to subtest samples by a single judge who evaluated motoric and 1 inguistic features of each subtest. Variable mean scores were determined and appropriate statistical measures were applied. Performances of the normal group subjects were not included in data analysis, but were used to illustrate graphically how the findings compared to normal.

Since comparison of the fluent and nonfluent groups ylelded only two variables with significant differences at any time interval, the two groups were combined to form an $\mathrm{N}$ of 20 .

When comparing the fluent and nonfluent group performances, differences between the two groups for all but two variables were not significant at any of the three sampling times. The two statistically significant variables were "unclassifiable" word types and letter 
substitution errors of spelling. Nonstatistical

differences were studied, and it was noted that most

differences occurred in Time I, but by Time II and again at Time III, the groups were largely indistinguishable.

Linguistic recovery appeared early in recovery (within 1-3 months) while motoric improvements occurred more slowly, with changes by $T$ ime II and III, although inter-group differences were slight.

After combining the two groups, most lingulstic changes occurred between Time I and II (about 45 percent), whlle fewer motoric changes occurred during this same time (about 30 percent).

\section{CLINICAL IMPLICATIONS}

The results of this study suggest that fluent and nonfluent aphasic patients have many common features in the ir graphic expression. Patlent performances rather than apriorl assumptions based on type of aphasia need to to be examined individually. Observation of the patients' performances during writing tasks may help to determine if the "unclassiflable" written errors seen in graphic production are paraphasic errors or whether they are "false starts" resulting from motor deficits. The efficacy of writing treatment was not examined; however, the type of analysis applied in thls study may be useful when formulating treatment objectives and assessing change. 


\section{IMPLICATIONS FOR FURTHER REASEARCH}

The outcome of thls study suggest several areas for future research using different methodologies.

The sampling procedures applied were limited in nature and did not allow for examination of extended narratlve writing. Differences in fluent and nonfluent aphasic Indivlduals' writing behavior might be better demonstrated by narrative writing tasks. Since mean scores from Subtests $B-E$ were utilized, differences between written naming, writing nouns to dictation and copying were not examined separately. Inter-task differences may have exsisted between the two groups. Furthermore, an analysis of graphic production in relation to Overall PICA scores at each test interval in relation to the amount of time patlents needed to complete Graphic Subtests A-E may also have demonstrated between-group differences.

The review of the literature indlcated that little examination of motoric influences on writing has been made. This study has demonstrated that aphasic patients have both motoric and IInguistic disorders affecting written performances. Analysis of "false starts" frequently observed in samples of aphasic patients' written behavior In this study, deserves attention in future studies. 


\section{REFERENCES}

BASSO, A., CAPITANI, E., and ZANOBIO, M.E. (1982). Pattern of recovery of oral and written expression and comprehension in aphasic patients. Behavioral Brain Research, 6, 115-128.

BASSO, A., TABORELLI, A., and VIGNOLO, L.S. (1978). Dissociated disorders of speaking. and writing in aphasia. Journal of Neurology, Neurosurgery, and Psychiatry, 41, 556-563.

BEAUVOIS,M., and DEROUESNE, J.(1981). Lexical or orthographic agraphia. Brain, 104, 21-49.

BENEDIKT, M. (1865). Uber aphasie, agraphie und verwandte pathologische. Cited by P. Marcie and H. Hecaen (1970) in Clinical neuropsychology, P. 93. London/New York: Oxford Universtiy Press.

BOONE D.R. and FRIEDMAN, H.M. (1976). Writing in aphasia rehabilitation: cursive vs manuscript. Journal of Speech and Hearing Disorders, 41, 523-529.

BRICKER, A.L., SCHUELL, H., and JENKINS, J.J. (1964). Effect of word frequency and word length on aphasic spelling errors. Journal of Speech and Hearing Research, 7, 183-192.

BROOKSHIRE, R.H.(1978). An introduction to aphasia. Minneapolis: BRK Publishers:

BROWN, J.E., LEADER, B.J. and BLUM, C.S. (1983). Hemiplegic writing in severe aphasia. Brain and Lanquage, 19, 204-215.

BUB, D. and KERTESZ, A. (1982). Evidence for lexicographic processing in a patlent with preserved wrltten over oral single word naming. Brain, 105, 697-717.

BUTFIELD, E., and ZANGWILL, O. L. (1946). Re-education in aphasia: a review of 70 cases. Journal of Neurology, Neurosurgery, and Psychlatry, 9,75-79.

DARLEY, F.L. (1982). Aphasla. Philadelphia: W.B. Saunders Comapny. 
DAVIS, G.A. (1983). A survey of adult aphasia. Englewood Cliffs, N.J.: Prentice Hall.

DEJERINE, J. (1891). Contrlbution a le'etude anatomopathologique et clinique des differentes varietes de cecite verbale. Memoires de las Societe de Biologie. Cited by P. Marcie and H. Hecaen (1970) in Clinical neuropsychology, P. 94. London/New York: Oxford Universtiy Press.

DUFFY, R.J. and ULRICH, S.R. (1976). A comparison of impairments in verbal comprehension, speech, reading and writing in adult aphaslcs. Journal of speech and Hearing Disorders, 46, 110-119.

EISENSON,J.(1973). Adult aphasla: Assessment and treatment. New York: Appleton-Century Crofts.

ELVIN, M.B. and OLDFIELD, R.C. (1951). Disabilities and progress in a dysphasic university student. Journal of Neurology, Neurosurgery and Psychiatry, 14, 118128 .

FRIEDERICI, A.D., SCHOENLE, P.W. and GOODGLASS, H.A. (1981). Mechanisms underlying writing and speech in aphasia. Brain and Lanquage, 13, 212-222.

GESCHWIND, N. (1971). Aphasia. New England Journal of Medicine, $12,654-656$.

GIBSON,J.W., GRUNER, C.R., KIBLER, R.J. and KELLY, F.J. (1966). A quantitative examination of the differences and similarities in written and spoken language. Speech Monographs, 33, 444-451.

GOLDSTEIN, K.(1948). Language and language disturbance. New York: Grune and Stratton.

GOODGLASS, H. and KAPLAN, E. $(1972$, a). The assessment of aphasla and related diserders. Phlladelphia: Lea and Feblger.

GOODGLASS, H. and KAPLAN, E. $(1972, b)$. The Boston Diagnostic Examination. Philadelphia: Lea and Febiger.

GOODGLASS, H. and HUNTER, M. (1970). A linguistic comparison of speech and writing in two types of aphasia. Jeurnal of Communication Disorders, 3, 2835. 
HEILMAN, K.M. (1975). Reading and wrlting dlsorders caused by central nervous system defects. Geriatrics, 30 , $115-118$.

HIER, D.B. and MOHR, J.P. (1977). Incongruous oral and written naming. Brain and Lanquage, 4, 115-126.

KEENAN, J. (1971). The detection of minimal dysphasia. Archives of Physlcal Medicine and Rehabilitation, 52, 257-269.

KENIN, M. and SWISHER, L. (1972). A study of pattern in aphasia. Cortex, 8, 56-68.

KERTESZ, A. (1980). Western Aphasia Battery. University of Ontario, London, Ontario, Canada.

KERTESZ, A. (1979). Aphasia and associated disorders. New York: Grune and Stratton.

MARCE, (1856). Memoire sur quel ques observations de physlologle pathologlque tendant a demontrer l'existence of principe coordinateur de l'ecriture. Comote-rendu de la Societe de Biologie, 3, 93-115. Cited by Marcie and Hecaen in Heilman and Valenste in (Eds.), (1979). Clinical neuropsychology, p.93. London/New York: Oxford University Press.

MARCIE, P. and HECAEN, H. (1979). Writing disorders assoclated with unllateral cortical lesions. In K.M. Hellman, and E. Valenste in (Eds.), Clinlcal neuropsychelogy. London/New York: Oxford University press. Pp 92-127.

MARGOLIN, D.I. and BINDER, L. (1984). Multiple component agraphia in a patient with atypical cerebral dominance: An error analysis. Brain and Lanquage, $22,26-40$.

MOHR, J.P., SIDMAN, M., STODDARD, L.T., LEICESTER, J. and ROSENBERGER, J.P. (1973). Evolution of the deflcit in total aphasia. Neurology, 23, 1302-1311.

OGLE, J.W. (1869). Aphasla and agraphia. St. George Hospital Report, 2, 83-122. Cited in Aaron Smith, (1971). Objective indices of severlty of chronic aphasia in stroke patients, P. 188. Journal of Speech and Hearing Disorders, $36-167$.

PERKINS, W.H. (1977). Speech Pathology. Saint Louis: C.V.Mosby. 
PIZZAMIGLIO, L. and ROBERTS, M. (1967). Writing in aphasia: A learning study. Cortex, 2, 250-257.

PORCH, B.E. (1981). Porch index of communicative ability administration. scoring and interoretation.

Albuquerque: Consulting Psychologists Press.

RUBIN, C. and BOLLINGER, R. (1983). Aphasla: treatment conslderations, graphic output. Toplas in Language Disorders, 3, 67-75.

SARNO, M. T., SILVERMAN, M. and SANDS, E. (1970). Speech therapy and language recovery in severe aphasla. Journal of Speech and Hearing Research, 13, 606-632.

SCHUELL, H.M., JENKINS, J.J. and JIMENEZ-PABON, E. (1964) Aphasia in adults. New York: Harper and Row.

SCHWARTZ, L., NEMEROFF, S. and REISS, M. (1974). An investigation of writing therapy for the adult aphasic. Cortex, 10, 278-283.

SERON, X., DELOCHE, G., MOULARD, G., and ROUSSELL, M.A. (1980). A computer based therapy for the treatment of aphasic subjects with writing disorders. Journal of Speech and Hearing Disorders, 45, 45-48.

SHALCICE, T. (1981). Phonological agraphia and the lexical route in writing. Brain, 104, 411-429.

SMITH, A., (1971). Objective indices of severity of chronic aphasia in stroke patients. Journal of Speech and Hearing Disorders, $35,167-204$.

SMITH, F., (1975). The relation between spoken and written language. In E.H. Lennenberg and E. Lennenberg (Eds.), Eoundations of language develooment. New York: Academic Press.

SPREEN, 0., (1968). Psycholinguistic aspects of aphasia. Journal of Speech and Hearing Research, 11, 467-487.

ULATOWSKA, K., BAKER, T., and STERN, R. F. (1979).

Disruption of written language in aphasia. In Whitaker, H. and Whitaker, H. (Eds.) Studies in neurolinguistics, Vol. 4. New York: Academic Press.

ULATOWSKA, K., HILDEBRAND, B.H. and HAYNES, S.M. (1978). A comparison of written and spoken language in aphasia. CAC Procedings. Minneaplolis: BRK publishers. 
WAPNER, W. and GARDNER, H., (1979). A study of spelling in aphasla. Braln and Lanquage, 7, 363-374.

WEIGL, E. (1975). On written language: Its acquisltion and 1 ts alexic-agraphlc disturbances. In $E$. $H$. Lennenberg and $E$. Lennenberg, Foundations of lanquage development. New York: Academlc Press. 


\section{APPENDIX A \\ PICA INSTRUCTIONS TO PATIENTS}

I. Test $A$

A. Requires the patient to use correct syntax, grammar and spelling in writing sentences about the function of each test object.

B. The cliniclan is to say, "In complete sentences, write here (point to test sheet) what you do with each of these." (gesture at test objects).

\section{Test B}

A. Requires the patient to write the names of objects without assistance, i.e., with only the objects as stimuli.

B. The cliniclan is to say, "Write here (point to paper) the name of each of these." (Gesture at objects.)

II Test C

A. Requires the patient to write the name of each object after the clinician says the name.

B. The clinician is to say, "Write here (point to sheet) the name of each one after I say it." (Say each object name)

IV. Test D

A. Requires the patient to write the name of the object after the clinlclan dictates the spelling.

B. The cliniclan is to say, "write each name here (polnt to sheet) after I spell it." 
v. Test $\mathrm{E}$

A. Requires the patient to copy the printed names of each item.

B. The clinician is to say, "Copy each of the se names (polnt to the word toothbrush) just below it. 


\title{
APPENDIX B
}

\author{
DEFINITIONAL CRITERIA
}

\section{Linguistic Parameters}

I. Subtest $A$

1. Spelling analysis

A. Correctly spelled words

B. Incorrectly spelled words

C. Unscorable due to poor leglbility, poor letter differentiation, incompletness, or being off task.

D. Words attempted

2. Word forms

A. Verbs, gerunds or infinitives. Words used to state action or function.

B. Nouns; person, place or thing.

C. Prepostions

D. Pronouns and possessives

E. Conjunctions

F. Articles

G. Adverbs and adjectives

H. Unclass ifiable; words that look like words, not crossed out, and consist of more than 1 or 2 letters.

II Subtests B-E, IIngulstic parameters

1. Spelling 
A. $100 \%$ correct. Whole word spelled correctly.

B. Letters added; spelling error due to addition of extraneous letters.

C. Letters deleted; spelling error due to deletion of letter or letters.

D. Transposed; letters sequentially transposed.

E. Letters Substituted

2. Word error types, or noun characteristics

A. Correct/recognizable; correct word or spelling error not influencing recognition of the target word.

B. Semantically related error; in class word substitution (eg., nlckel for quarter).

C. Literal paraphasla; single letter or single syllable errors within words that when spoken aloud sound close to the target word (eg., pentil for pencill).

D. Neologisms; leglble but non-meaningful words.

E. Perseverations; response repetitions, recurring words.

\section{Motoric Parameters}

\section{I Subtests $A-E$}

1. Letter size

A. Larger than $1 \mathrm{~cm}$. Most (75-100 percent) words are larger than $1 \mathrm{~cm}$; does not include letters such as $f, g, l$, etc.

B. 1/2-1 cm; 75-100 percent of words are withln this size range.

C. Less than $1 / 2 \mathrm{~cm}$ in $\mathrm{s} / \mathrm{ze}$.

2. Letter style (type of handwrlting)

A. Cursive, or script style handwriting. 
B. Manuscript; letter by letter printed hand writing.

c. Mixed; combined types of handwriting.

3. Line execution (appearance of letter lines)

A. Tremulous, includes wavy, shaky lines.

B. Nonfluid; not smooth flowing in appearance, contains obvious motoric difficulties.

C. Nonhorizontal; wrlting on plane of 15 degrees or more.

4. Letter execution

A. Angiguous; can not be certain of target letter.

B. Letter reversals; letters produced in a mirrored or reversed manner $(e . g ., p / g, s / z)$.

C. Overlapping or run together letters.

D. Marked over letters 
APPENDIX C

LINGUISTIC VARIABLES

RAW DATA

T-Tests

VARIABLE GROUP MEAN I $P$ MEAN II $P$ MEAN III $P$

\begin{tabular}{|c|c|c|c|c|c|c|}
\hline Verbs & 2 & $\begin{array}{l}5.000 \\
3.300^{0.343}\end{array}$ & $\begin{array}{r}10.800 \\
9.800\end{array}$ & 0.730 & $\begin{array}{r}13.000 \\
9.800\end{array}$ & 0.156 \\
\hline Prepositon & 1 & $\begin{array}{l}2.800 \\
3.300^{0.794}\end{array}$ & $\begin{array}{l}6.300 \\
4.600\end{array}$ & 0.363 & $\begin{array}{l}7.200 \\
4.800\end{array}$ & 0.160 \\
\hline Pronouns & 1 & $\begin{array}{l}0.900 \\
3.500^{0.286}\end{array}$ & $\begin{array}{l}3.100 \\
5.500\end{array}$ & 0.391 & $\begin{array}{l}3.800 \\
7.300\end{array}$ & 0.202 \\
\hline Articles & 2 & $\begin{array}{l}2.600 \\
0.800^{0.23}\end{array}$ & $\begin{array}{l}4.800 \\
3.800\end{array}$ & 0.537 & $\begin{array}{l}7.200 \\
5.200\end{array}$ & 0.35 \\
\hline Nouns & 1 & $\begin{array}{l}3.400 \\
7.000^{0.127}\end{array}$ & $\begin{array}{l}11.700 \\
11.300\end{array}$ & 0.868 & $\begin{array}{l}13.700 \\
12.900\end{array}$ & 0.72 \\
\hline
\end{tabular}


VARIABLE GROUP MEAN I $P$ MEAN II $P$ MEAN III $P$

\begin{tabular}{|c|c|c|c|c|c|c|}
\hline Adj., Adverb & 2 & $\begin{array}{l}1.200 \\
0.400^{0.177}\end{array}$ & $\begin{array}{l}0.700 \\
1.300\end{array}$ & 0.329 & $\begin{array}{l}0.900 \\
5.200\end{array}$ & 0.168 \\
\hline Unclass. & 1 & $\begin{array}{l}11.900 \\
2.700\end{array}$ & $\begin{array}{l}3.500 \\
4.500\end{array}$ & 0.650 & $\begin{array}{l}4.200 \\
2.400\end{array}$ & 0.441 \\
\hline Correct & 1 & $\begin{array}{l}4.640 \\
5.120^{0.679}\end{array}$ & $\begin{array}{l}6.680 \\
6.650\end{array}$ & 0.974 & $\begin{array}{l}7.930 \\
8.110\end{array}$ & 0.837 \\
\hline Deleted & 2 & $\begin{array}{l}0.530 \\
1.070^{0.144}\end{array}$ & $\begin{array}{l}0.450 \\
0.592\end{array}$ & 0.745 & $\begin{array}{l}0.415 \\
0.390\end{array}$ & 0.916 \\
\hline Substitution & 1 & $\begin{array}{l}1.940 \\
0.960^{0.043}\end{array}$ & $\begin{array}{l}1.110 \\
1.850\end{array}$ & 0.336 & $\begin{array}{l}1.180 \\
0.720\end{array}$ & 0.212 \\
\hline Paraphas ia & 1 & $\begin{array}{l}1.020 \\
1.460^{0.226}\end{array}$ & $\begin{array}{l}1.420 \\
1.170\end{array}$ & 0.430 & $\begin{array}{l}1.010 \\
0.585\end{array}$ & 0.220 \\
\hline Neologisms & 1 & $\begin{array}{l}4.620 \\
2.690\end{array}$ & $\begin{array}{l}1.220 \\
1.085\end{array}$ & 0.800 & $\begin{array}{l}0.760 \\
0.880\end{array}$ & 0.807 \\
\hline Incorrect & 1 & $\begin{array}{l}5.100 \\
2.600^{0.241}\end{array}$ & $\begin{array}{l}4.200 \\
3.900\end{array}$ & 0.849 & $\begin{array}{l}5.400 \\
5.100\end{array}$ & 0.873 \\
\hline Unscorable & 1 & $\begin{array}{l}14.200 \\
6.300^{0.101}\end{array}$ & $\begin{array}{l}4.900 \\
7.900^{\circ}\end{array}$ & 0.332 & $\begin{array}{l}3.500 \\
6.900\end{array}$ & 0.313 \\
\hline
\end{tabular}


VARIABLE GROUP MEAN I $P$ MEAN II $P$ MEAN III $P$

$\begin{array}{llllll}\text { Attempted } & 1 & 34.100 & 43.300 & 47.700 & \\ & 2 & 24.500^{0.245} & 44.100^{0.931} & 52.200\end{array}$

MOTORIC VARIABLES

\begin{tabular}{|c|c|c|c|c|c|}
\hline Within $\mathrm{cm}$ & $\begin{array}{l}1 \\
2\end{array}$ & $\begin{array}{l}62.800 \\
63.950^{0.947}\end{array}$ & $\begin{array}{l}74.520 \\
81.600\end{array}$ & 0.638 & $\begin{array}{l}79.400 \\
93.680\end{array}$ \\
\hline Nonfluld & $\begin{array}{l}1 \\
2\end{array}$ & $\begin{array}{l}42.400 \\
57.950^{0.348}\end{array}$ & $\begin{array}{l}32.920 \\
46.590\end{array}$ & 0.418 & $\begin{array}{l}28.950 \\
37.500\end{array}$ \\
\hline
\end{tabular}

Ambiguous

1

3.940

0.902

4.580

3.880

$3.810^{\circ}$

0.092

0.153

2

2.650

1.870

Overmark

2.880

2.140

1.360

2

$2.860^{0.987}$

2.910

0.516

2.360

0.051

Cursive

1

39.000

40.600

$37.500^{0.942} 46.000$

45.600

2

0.796

$45.250^{0.986}$

Manuscript

60.400

$$
0^{0.918} \begin{array}{cc}
59.000 \\
54.000^{0.810}
\end{array}
$$

62.500

54.000

54.750

0.969

Group I, Fluent

Group II, Nonfluent 